
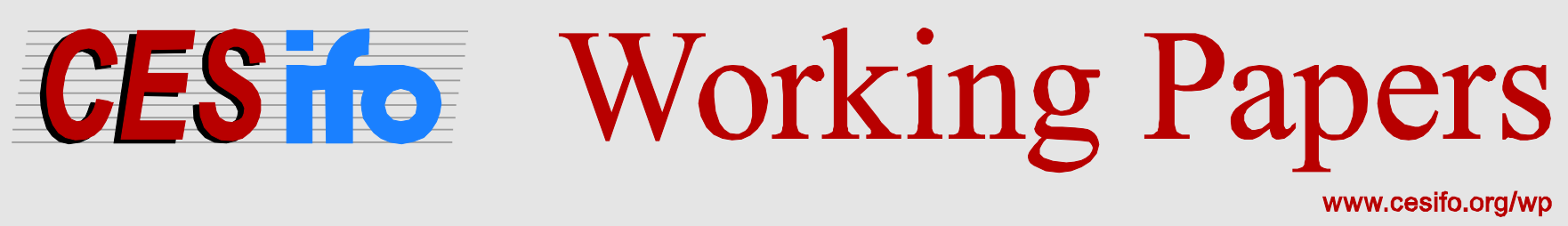

\title{
Waiting Longer Before Claiming, and Activating Youth. No Point?
}

\author{
Bart Cockx \\ Eva Van Belle
}

\section{CESIFO WORKING PAPER NO. 6104 \\ CATEGORY 4: LABOUR MARKETS \\ SEPTEMBER 2016}
An electronic version of the paper may be downloaded
- from the SSRN website:
- from the RePEc website:
- from the CESifo website: WwW.SSRN.com
www.RePEc.org
www.CESifo-group.org/wp

\section{CESifo}




\title{
Waiting Longer Before Claiming, and Activating Youth. No Point?
}

\begin{abstract}
In Belgium school-leavers are entitled to unemployment benefits after a waiting period and eligible to intensified counselling and training in the Youth Work Plan (YWP) if a job is not found within three months. The length of the waiting period and eligibility to the YWP are sharply determined by two distinct age thresholds. These are exploited to estimate the impact of these policies on the transition rate to employment and on the quality of work. Both policies increase job finding only slightly and insignificantly. The accepted wage is unaffected, but the number of working days falls and, hence, also earnings.
\end{abstract}

JEL-Codes: J640, J650, J680.

Keywords: youth unemployment, policy evaluation, regression discontinuity design, survival analysis, quality of employment.

\author{
Bart Cockx* \\ Sherppa \\ Ghent University \\ Sint-Pietersplein 6 \\ Belgium - 9000 Gent \\ bart.cockx@ugent.be
}

\author{
Eva Van Belle \\ Sherppa \\ Ghent University \\ Sint-Pietersplein 6 \\ Belgium - 9000 Gent \\ eva.vanbelle@ugent.be
}

*corresponding author

September 20, 2016

We are obliged to the Flemish Public Employment Agency ("VDAB”) and Geert Degraeve, and the Cross Roads Bank of Social Security and Chris Brijs for the delivery of the data. We gratefully acknowledge financial support of the Flemish government through the "Policy Research Centre Work and Social Economy”. The views expressed are those of the authors and not of the Flemish government. 


\section{Introduction}

The Great Depression of 2008 has had a devastating impact on youth unemployment in Europe. By 2012 the youth unemployment rate in the European Union (EU27) had attained an unprecedented height of 22.8 per cent, causing multiple European countries to raise the alarm bell. In this context in 2009 the Flemish ${ }^{1}$ government introduced a Youth Work Plan (YWP) in which young unemployed job seekers below the age of 25 were followed-up more intensively after the first month of unemployment. In 2012 the Belgian government extended, for schoolleavers aged less than 26, the waiting period before entitlement to unemployment insurance (UI) benefits by three months, from nine to twelve months. This study aims at evaluating the effectiveness of these two policies.

Belgium is one of the few countries in the world in which school-leavers need not have worked to be eligible to (flat rate) non-means-tested UI benefits. To the best of our knowledge, Australia and New-Zealand are the only other OECD countries that share these features of UI, even for non-school-leavers. A waiting period in UI is usually justified as a means to discourage voluntary quits from jobs as well as temporary lay-offs by firms (Fredriksson and Holmlund 2006, p. 366). This argument cannot apply for school-leavers, because they enter the labour market for the first time. Rather, the extension mainly aimed at reinforcing job search incentives.

We are not aware of any other study that investigates the impact (of an extension) of the waiting period. This is probably because the waiting period, if it exists, mostly lasts only a couple of days. Even in Australia and New-Zealand, the waiting period ranges only between one and two weeks (Tatsiramos and van Ours, 2014, Table 2). In these countries job search incentives are rather induced through much stricter job search requirements and follow-up by counsellors, especially in Australia (Langenbucher 2015). As mentioned, in Flanders, youths below the age of 25 are also counselled more intensively early on in the unemployment spell than older job seekers. Hence, we aim at disentangling the impact of both policies.

Our research strategy consists in exploiting a discontinuity in the duration of the waiting period at age 26 that was present prior to the reform in 2012: school-leavers younger than 26 were eligible to UI after 9 months, while those older had to wait one year. We investigate whether this discontinuity translates in a discontinuity in a number of labour market outcomes and,

\footnotetext{
${ }^{1}$ Belgium is a federal state of three regions. Flanders is the Dutch speaking region in the North.
} 
hence, provides causal evidence on the effectiveness of the 2012 reform (Imbens and Lemieux 2008; Lee and Lemieux, 2010). First, we consider the effect on unemployment duration and transitions from unemployment to employment. Search theory predicts that the longer waiting period may not only induce youth to search harder for jobs, but also to be less selective in accepting job offers (Mortensen 1977). We therefore also consider the effect on a number of indicators of job quality, such as the daily wage, the time spent in employment, the incidence of part-time work and annual earnings from salaried employment. This identification strategy requires a simultaneous evaluation of the YWP, because participation in it is also conditioned on an age threshold. In the analysis we will therefore allow for two potential age discontinuity points.

The waiting period starts after school-leavers first registration as job seeker at the regional Public Employment Service (PES). Our analysis is based on a follow-up of all first registrations in Flanders, from July to October between 2008 and 2010. In order to obtain information on job quality, these registers are matched to those of diverse social security institutions. The population of interest is restricted to individuals with at least a bachelor's degree to avoid confounding the impact of the extension of the waiting period with that of a hiring subsidy targeted to youth with a lower level of education, which applied also below age 26 .

The remainder of this paper is structured as follows. In Section 2 we describe in more detail the institutional setting and, in particular, the features that may influence the causal regression discontinuity design (RDD). In Section 3 we formulate a number of expectations based on economic theory. Section 4 describes the data and Section 5 the empirical approach. Section 6 reports the results of our analysis, including some sensitivity analysis. Section 7 concludes with a summary of the empirical findings, and with a brief discussion of policy implications and the limitations of this study.

\section{Institutional Framework}

\subsection{UI, the Waiting Period and Recent Reforms Regarding Youth}

In Belgium a worker is eligible to UI in two instances: (i) after graduation from school conditional on a waiting period; (ii) after involuntary dismissal from a sufficiently long-lasting job. School-leavers are entitled to flat rate benefits, which depend on the family status and are non-means tested. In contrast to many other countries there is no time limit to the payment of UI benefits. 
Before January 2012 the required waiting period for eligibility to UI lasted 9 months if the applicant was younger than 26 at the end of this period, while it lasted 12 months for those older than 26. The period starts after school completion from the first registration as job seeker at the regional PES. Since the secondary school year usually runs from 1 September to 30 June, first registrations occur usually in July. However, regulations state that the waiting period cannot start before August 1, unless registration starts after drop-out in the middle of the school year. In order to discourage drop-out, eligibility is conditional on a minimum acquired level of education: at least six successful years of secondary education for those in the general track preparing for higher education, while for the technical vocational or artistic track three successful years is sufficient.

During the waiting period one is supposed to be actively seeking jobs. Before 2012 search effort was not explicitly monitored during the waiting period, but the PES scheduled periodical contacts with caseworkers which were more intensive for youths below the age of 25 (see the description of the "Youth Work Plan" below). At these contacts participation in counselling or training could be proposed. A job seeker refusing participation risks being imposed a sanction by the federal UI agency, but from an international perspective the imposed requirements on job seekers are relatively lenient.

Any intervening employment spell or participation in short- to medium-run part-time vocational training counts for the waiting period. By contrast, participation in longterm or full-time training programmes, or resumption of full-time education, resets the waiting time to zero. The waiting period is interrupted (without reset) for any other intervening period of inactivity, such as sickness or incarceration.

Since January 1, 2012 the waiting period for those younger than 26 was extended by three months, so that it became as long as that for the older school-leavers. Furthermore, two additional restrictions were imposed on UI for school-leavers. First, a time limit of three years was imposed on the entitlement to UI benefits as schoolleaver. However, this time limit applies only before the age of 30 for individuals living with other household members with income above some threshold. Second, job search effort is evaluated every 6 months since 2012 and school-leavers are only eligible to UI if they satisfy the job search requirements. Before 2012 these evaluations were only 
implemented after 15 or 21 months, respectively for those younger or older than 25 . In 2015, the UI scheme for school-leavers was further reformed. UI benefits can no longer be claimed if older than 25 and school-leavers younger than 21 must at least have successfully completed six years of secondary education.

\subsection{Policies Potentially Threatening the RDD}

In the period of analysis (2008-2012) several hiring subsidies were targeted to youth below the age of 26. These could potentially threaten our discontinuity design. Two policies, a flat rate reduction in employer's social security contribution and the socalled “Activa” advantages, do not pose a threat because they do not constitute an age discontinuity or the discontinuity is at a different point. Between 2010 and 2011 the Activa advantages were temporarily replaced by the so-called “Win-Win". This temporary measure was introduced to fight the persisting crisis since the Great Recession of 2008. The Win-Win was targeted at youth with at most a secondary school degree and who were less than 26 years old at hiring. By targeting youth below the same age threshold as the one at which the waiting period is extended, this policy in principle threatens our design. However, since the subsidy is targeted at youths with at most a secondary school degree, the discontinuity design remains valid if the analysis is restricted to youths with a higher educational degree: bachelors or masters. Not many observations are lost by imposing this restriction, since the analysis focuses on youths entering unemployment directly after their studies. Within this target group only a small minority does not have a higher educational degree around the age discontinuity of 26 years.

In 2008 the Flemish PES introduced the Youth Work Plan (YWP) as a pilot project targeted at low-educated youth in the largest Flemish cities. From 2009 onwards the YWP was extended to all youth younger than 25 one month after registration. The PES sends emails with job vacancies to all job seekers from the moment of their registration. The YWP consists of a set of specific actions targeted at those job seekers who did not yet find a job three months after registration. At that moment a PES counsellor contacts the job seeker by telephone. If impediments to work are detected, the job seeker is invited for a meeting at the PES and counselling or training actions are proposed. If no action has been undertaken after this first contact and the job seeker is still unemployed three months later, he or she is invited directly to a meeting with a PES counsellor who 
may then propose to undertake particular actions. To the extent that the PES strictly denies these services for those older than 25 one month after registration and the YWP is effective, this could generate an age discontinuity close to the one that determines the length of the waiting period. For the latter the discontinuity occurs at 26,9 months after registration as job seeker. If the age is measured 9 months after registration, the potential age discontinuity of the YWP would occur at the age of 25 and 8 months. ${ }^{2}$ In the analysis below we therefore explicitly allow for this second discontinuity.

\section{Theoretical Expectations and Existing Evidence}

\subsection{Lengthening the Waiting Period}

A waiting period is the mirror image of a time limit on UI eligibility. With a time limit the job seeker is informed at entry that the UI benefit will expire after a predetermined period. In the case of a waiting period, UI benefits are zero at the onset of unemployment and will become strictly positive after a predetermined period. We expect therefore that the predicted behaviour should be the mirror image of the one predicted for the case of time limit.

Mortensen (1977) is the first to use non-stationary job search theory to describe the predictions of a time limit in UI on the job search behaviour of rational forward looking individuals. He proves that a job seeker gradually increases job search effort and reduces the reservation wage (or, equivalently, increases the job acceptance probability) as she approaches the moment of benefit exhaustion. This empirical prediction has been largely confirmed in the literature (Tatsiramos and van Ours, 2014), although that empirical studies generally find a more abrupt than predicted increase in the job finding rate just before benefit exhaustion, followed by drop immediately afterwards. ${ }^{3}$

In Figure 1 we depict the predictions of standard job search theory of an extension of the waiting period from 9 to 12 months. Before the extension the unemployed are not yet claiming UI benefits. Hence, they will then search harder for jobs than when they are entitled to UI.

\footnotetext{
${ }^{2}$ For the YWP the age (25 years) is measured one month after registration. Consequently, if age is measured at the end of the waiting period, i.e. 9 months after registration, participants in the YWP should be younger than 25 years and 8 months at that point. Recall that for those registered as job seeker in July the discontinuity is measured slightly later, i.e. 9 months after August 1, starting point of the waiting period for these individuals.

${ }^{3}$ Mortensen (1977) show that such spikes in the job finding rate could theoretically emerge if income and leisure are strict substitutes. Boone and van Ours (2012), however, explain that such an assumption is not realistic. Card et al. (2007) attribute part of the spike to measurement error, but according to Boone and van Ours $(2012$, p.415) this cannot be the full story. Last mentioned authors argue that the spike may be generated by the fact that UI recipients may prefer delaying the beginning of a job until unemployment benefits have expired.
} 
Nevertheless, in anticipation of the entitlement, they will gradually decrease job search effort until the flat rate benefit is paid out. Since this benefit never expires, job search effort remains constant after that point. An extension of the waiting period from 9 to 12 months should induce a parallel shift of the search effort to the right, because rational forward looking individuals make identical decisions in case the future profile of UI benefits is the same. Job search theory therefore predicts that an extension of the waiting period should unambiguously increase the job finding rate throughout the unemployment spell. Depending on the form of the utility function, the time profile may be concave or convex (linear, for simplicity, in Figure 1) close to the start of benefit entitlement. Hence, we cannot make general predictions regarding the unemployment duration at which the maximal impact should be attained. However, because job seekers discount the future, the difference in job search behaviour is expected to diminish closer to the onset of the unemployment spell.

Figure 1: Stylized Impact on the Job Finding Rate of an Extension of the Waiting Period

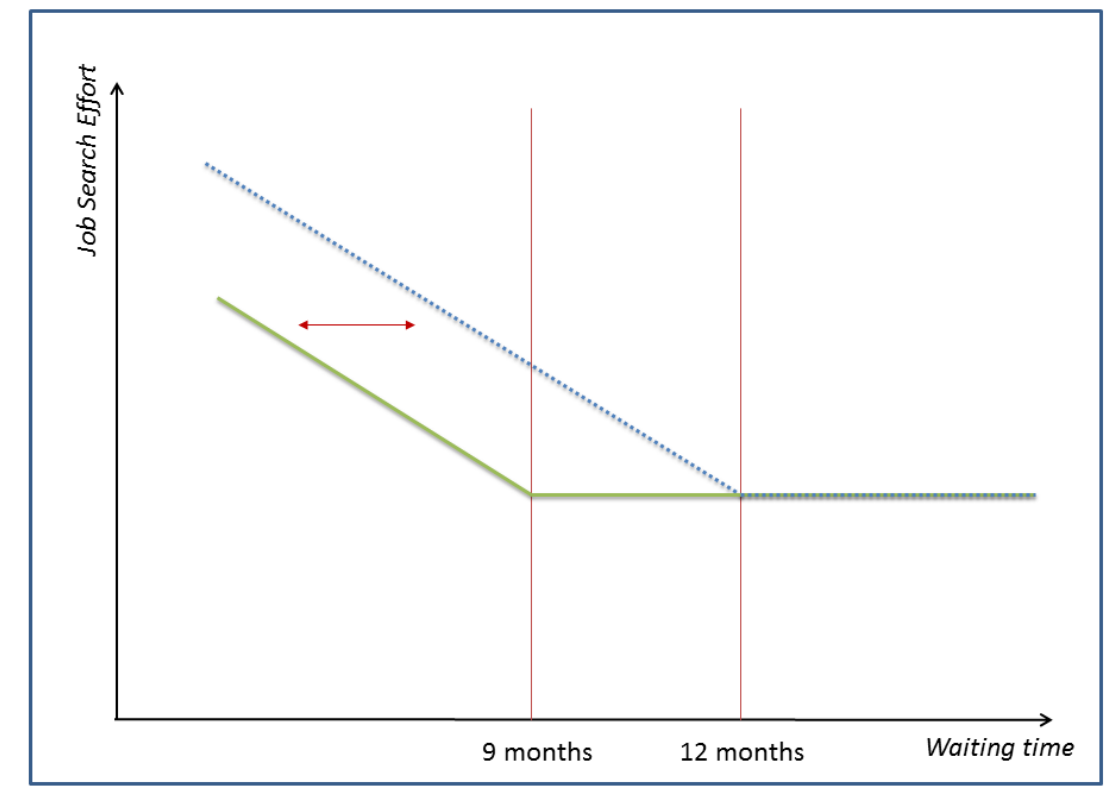

One may question that the aforementioned predictions realise for at least two reasons. First, the predictions are based on the assumption that other income sources are exogenously fixed. This may not be realistic for school-leavers. School-leavers may be financially supported by their parents during the waiting period and only become financially independent from the moment they find a job or are entitled to UI benefits. Whether this is possible may depend on the financial situation of parents, which we will test for in the empirical analysis.

A second reason why the aforementioned predictions may not realize is that they are based on 
the assumption that job seekers form rational and unbiased expectations about the likelihood of finding jobs. Since the seminal work of Tversky and Kahneman (1974) there is, however, growing evidence that expectations can be severely biased. For example, there is now broad evidence that individuals are overly optimistic regarding positive events and pessimistic with respect to negative events (Moore and Healy 2008), in particular that job seekers strongly underestimate how long they will remain unemployed (Spinnewijn 2015), and that job seekers behave according to time-inconsistent (hyperbolic) time preferences (Della Vigna and Passerman 2005). Both biased beliefs and inconsistent time preferences tend to make job seekers less responsive to future incentives (Spinnewijn 2015; Paserman 2008). Hence, an extension of the waiting period may have much weaker behavioural impact than the one predicted by the standard job search model.

Existing empirical evidence nevertheless shows that financial incentives do play a role, and that the predictions of the standard job search model are not completely washed away by nonrational or biased expectation formation. Both the benefit level and the potential duration of benefits is found to significantly affect the job search effort of unemployed job seekers. By contrast, the evidence with regards the job acceptance behaviour is less clear-cut. For instance, job search theory predicts that extensions of the potential period of benefit receipt should increase the reservation wage and positively affect the job quality. However, the empirical evidence regarding the effect of the design features of UI on the quality of the subsequent job is mixed. Some studies find no effect, others small positive but heterogeneous effects. The latter suggests that there might be only an impact on a smaller set of liquidity constrained unemployed individuals. $^{4}$

\subsection{Intensifying Counselling and Training for Youth}

The empirical evidence on the effects of an intensification of counselling and training for youth such as in the aforementioned YWP in Flanders is mixed. In their most recent meta-analysis of active labour market programme evaluations Card et al. (2015) find that "job search assistance and sanction programs that emphasize "work first" have relatively large short term impacts on average. Training and private sector employment programs have smaller short term impacts but larger effects in the medium and longer runs." Since the YWP comprises the two components, it might be expected to increase the job finding rate of those who are assisted in searching for jobs, while a locking-in effect may result for participants in training programmes. However,

\footnotetext{
${ }^{4}$ See Tatsiramos and van Ours (2014) for a recent survey of this literature.
} 
active labour market programs are also found to generally work less well for youth than for a prime aged population.

Experimental evidence in Denmark has shown that a combination of meetings, job search courses and early activation could significantly enhance transitions from unemployment to employment. In this case the treatment seemed even particularly effective for youth (Graversen and van Ours 2008). Empirical evidence shows that these large treatment effects are largely due to the intensification of the meetings and the threat of participation requirements rather than from the participation in active labour market programmes itself (Rosholm 2008, Vikström et al. 2013, Pedersen et al. 2012). In Denmark the unemployed receive 6-7 meetings during the first 13 weeks. The intensity of meetings is therefore much higher than in the Flemish YWP where youth are invited to a first meeting only from the third month. Moreover, even if participation is in principle mandatory this is, in contrast to Denmark, not very strictly enforced. For these reasons we cannot expect as strong effects of the YWP as the intensified early meetings and activation in Denmark.

\section{Data}

\subsection{Data Sources and Sample Selection Criteria}

The empirical analysis is based on Flemish PES register data of the full population registering for the first time as job seeker between July 1 and October 31 for the years 2008 through 2013. The regional PES register data only informs about the potential type of UI entitlement - based on sufficient work experience or educational attainment - not about the effective benefit entitlement, neither about the activity state (education, employment or inactivity) prior to the first registration. They cannot, hence, distinguish between youths who just left school and those who had some intervening spell of employment or inactivity. Since employment spells count for the waiting period and we do not have reliable information on the exact starting date of employment, we exclude the latter group from the analysis as to focus on youths who are unemployed at the onset of the waiting period. ${ }^{5}$ We therefore restrict the population in the following ways. First, since in Belgium the school year ends on June 30 and the academic year in university starts in the last weeks of September, after the exam retakes, restricting first registrations to the July-October period targets the group registering immediately after

\footnotetext{
${ }^{5}$ The onset of the waiting period coincides for this group with the first registration at the regional PES, except if this registration occurs in July. In the latter case the waiting period starts on August 1 (see Section 2.1).
} 
graduation. ${ }^{6}$ Second, we requested the Cross Roads Bank of Social Security (CBSS) to match the register data of the PES to those of the different federal institutions of social security in Belgium. These data contain quarterly information on salaried and self- employment (since 2007) and monthly information on receipt of UI insurance benefits. Based on this information we dropped all individuals who (i) were observed in employment prior to the first registration in the Flemish PES, (ii) were reported to have left unemployment for a job according to the PES, but were not found to be unemployed in the social security dataset, and (iii) who were observed to be entitled to UI earlier than they could have been based on their first registration date and their age. The latter inconsistency is likely the consequence of measurement error, since there are only few.

We mentioned in Section 2.2 that we could only include school-leavers with a bachelors or master degree in the analysis, because otherwise the RDD would be confounded by a wage subsidy targeted at low educated youth. Furthermore, since the focus of the analysis is on the impact of the extension of the waiting period and the identification strategy is based on the discontinuity in the duration of the waiting period at the age of 26, we restrict the sample of analysis to an age window of 1.5 years to the left and to the right of this age. We do not consider a wider window because there are only very few individuals (178) who are older than 27.5 years. Finally, we restrict the analysis to the youths entering the labour market between 2008 and 2010. The population entering in 2011 is not considered, because the waiting period of those younger than 26 was extended in the middle of their waiting period, on January 1, 2012. The entrants in 2012 are retained for a placebo analysis. The 2013 inflow is ignored, because the available PES registration data are right censored at the end of November 2013. In conclusion, while the initial population consists of 151,744 individuals, the final sample size retained for the analysis reduces to 5,495 individuals of whom 4,495 are younger than 26 and 1,000 older. Appendix A indicates how the sample size diminishes as particular selection criteria are imposed.

\subsection{Descriptive Statistics}

Table 1 reports the descriptive statistics of the explanatory variables retained in the empirical analysis. All variables except the household type originate from the PES registers and are measured at the first registration in the Flemish PES. The household type originates from the

\footnotetext{
${ }^{6}$ For a few observations the unemployment spell was recorded to start at a different date than the first registration. These observations were dropped from the analysis.
} 
CBSS and is measured on December 31 of the year preceding the first registration at the PES. Descriptive statistics are reported for the complete sample, for the group younger than 26 (between 24.5 and 26) and for the group aged at least 26 (between 26 and 27.5). The age is calculated (with daily precision) at the (counterfactual) end of the waiting period.

Table 1: Descriptive Statistics of Explanatory Variables

\begin{tabular}{|c|c|c|c|}
\hline & Total & $<26$ & $\geq 26$ \\
\hline Number of Individuals & 5,495 & 4,495 & 1,000 \\
\hline Mean age at the end of the waiting period & 25.36 & 25.10 & 26.52 \\
\hline Variable & $\%$ & $\%$ & $\%$ \\
\hline Gender: Female & 47.68 & 48.59 & 43.60 \\
\hline Driver license (yes) & 99.49 & 99.51 & 99.40 \\
\hline Education: master (other = bachelor) & 75.18 & 74.82 & 76.80 \\
\hline Good knowledge of Dutch & 94.54 & 94.82 & 92.80 \\
\hline $\begin{array}{c}\text { Nationality: Belgian } \\
\text { Household type: }\end{array}$ & 98.23 & 98.40 & 97.50 \\
\hline Single or couple with children & 0.42 & 0.42 & 0.40 \\
\hline Single & 3.73 & 3.38 & 5.30 \\
\hline Other (couple w/o child., institution,...) & 3.55 & 3.43 & 4.10 \\
\hline $\begin{array}{l}\text { Child living at parent's house } \\
\text { Year of first registration at PES }\end{array}$ & 83.99 & 84.92 & 79.80 \\
\hline 2008 & 32.67 & 33.24 & 34.60 \\
\hline 2009 & 34.43 & 34.73 & 33.10 \\
\hline 2010 & 32.90 & 33.04 & 32.30 \\
\hline Month of first registration at PES & & & \\
\hline July & 47.90 & 48.92 & 43.30 \\
\hline August & 18.89 & 19.18 & 17.60 \\
\hline September & 27.01 & 26.14 & 30.90 \\
\hline October & 6.21 & 5.76 & 8.20 \\
\hline Equivalent household income* & 23’978 & 24’226 & $22 ’ 845$ \\
\hline
\end{tabular}

Note: Descriptive statistics of sample of analysis for the RDD. First registration at Flemish PES in July-October 2008-2010 for those aged between 24.5 and 27.5 years 9 months after registration. All variables except the household type originate from the PES registers and are measured at the first registration. The household type comes from the CBSS and is measured on December 31 of the year preceding the first registration. ${ }^{*}$ Measured in the calendar year prior to first registration as job seeker. This includes labour market earnings and social security allowances of all household members excluding the school-leaver. The income has been scaled by the "OECD-modified scale" assigning a value of 1 to the household head, of 0.5 to each adult household member older than 18 (including the school-leaver) and 0.3 to each child. Reported statistics are calculated after dropping 74 missing observations. In the benchmark analysis these 74 observations are retained, because this analysis does not condition on this variable.

There is an asymmetry in the size of the sample around the age discontinuity of 26 . The majority in the retained sample is younger than 26. This is because most individuals complete education before this age. Youths ending higher education so late typically have repeated a couple of grades, since 22 or 23 is the typical age at which a master degree without any schooling delay would be attained. It also explains why about three quarters of the sample have a master degree: bachelors must have even more schooling delay to be observed in this age range.

The vast majority of the retained individuals have the Belgian nationality, a good 
knowledge of Dutch and a driver's licence. This mirrors the fact that migrants rarely complete higher education in Belgium. More than $80 \%$ of the sampled individuals were officially residing at their parent's house at the end of the year preceding the first registration as job seeker at the PES. This comes as no surprise, since, by the imposed selection criteria, these individuals should have been in full-time education at that moment. At the same time this is an indication that the sampled individuals are still financially dependent on their parents and that, hence, the extension of the waiting period might not have any important financial impact (Section 3).

As expected, about one third of the sample starts in each of the three retained starting years: 2008, 2009 and 2010. About 50\% of the retained sample registers in July. This is because a regular student graduates in June. This share is somewhat smaller for those older than 26. This may reflect that the older group must have accumulated more schooling delay and is more likely to have to retake exams in September. With respect to the other variables the fractions are relatively balanced over the age groups, except for gender. Women are less likely to be older than 26 .

Table 2 displays the descriptive statistics of the outcome variables of interest. We report the number of observations for which we have non-missing values, and the mean and percentiles (5, 25, 50, 75 and 95) of its distribution. The first variable of interest is the unemployment duration. This variable comes from the PES registers and is measured at the end of each calendar month. Temporary exits within the month are not recorded. This may lead to a slight measurement error, an issue to which we will return in Section 6. A second consequence of measuring the unemployment status at the end of the month is that our data are left truncated: the PES did not select individuals at the actual first registration date, but at the end of the calendar month of this registration. This means that individuals who have left unemployment between registration and the end of the month are not retained. Note, however that we do have exact information at which date the registration of these individuals occurred, so that we can exactly determine the potential end date of the waiting period for each individual.

Unemployment duration is right censored at the end of the observation period in November 2013. In the sample of analysis only 12 observations are right censored, which is negligible and a feature that will be exploited in the empirical analysis. The PES identifies at the end of each month whether an individual has left unemployment and, if so, the registers inform 
whether the exit was to employment or another destination, which we label "inactivity”. In Table 2 the third variable reports the descriptive statistics for the unemployment duration in case of an exit to employment, while the fifth one considers exits to inactivity only. Relatively few individuals (396) leave to inactivity, so that the general unemployment distribution hardly differs. Median duration is 4 months, implying that only a minority is unemployed throughout the complete waiting period. 95\% has left unemployment within one year.

Table 2: Descriptive Statistics of Outcome Variables

\begin{tabular}{|c|c|c|c|c|c|c|c|}
\hline Variabele & $\begin{array}{c}\# \\
\text { observations }\end{array}$ & average & $5 \%$ & $25 \%$ & $50 \%$ & $75 \%$ & $95 \%$ \\
\hline $\begin{array}{c}\text { Unemployment } \\
\text { duration }\end{array}$ & 5,495 & 4.98 & 2 & 3 & 4 & 6 & 12 \\
\hline $\begin{array}{l}\text { excluding right } \\
\text { censored obs. }\end{array}$ & 5,483 & 4.89 & 2 & 3 & 4 & 6 & 12 \\
\hline $\begin{array}{c}\text { ending in } \\
\text { employment }\end{array}$ & 5,086 & 4.81 & 2 & 3 & 4 & 6 & 11 \\
\hline $\begin{array}{c}\text { ending in } \\
\text { salaried } \\
\text { employment }\end{array}$ & 4,785 & 4.79 & 2 & 3 & 4 & 6 & 11 \\
\hline $\begin{array}{l}\text { ending in } \\
\text { inactivity }\end{array}$ & 396 & 5.73 & 2 & 3 & 4 & 7 & 14 \\
\hline Working days $^{1}$ & 4,785 & 243.3 & 72 & 211 & 270 & 295 & 324 \\
\hline Daily wage $(€)^{2}$ & 4,259 & 106.7 & 74.7 & 92.6 & 104.5 & 119.2 & 144.2 \\
\hline $\begin{array}{c}\text { Daily wage }(€) \\
\text { (corrected) }^{3}\end{array}$ & 4,540 & 109.5 & 77.9 & 95.8 & 106.7 & 123.1 & 147.1 \\
\hline Earnings $^{5}$ & 4,689 & 26,039 & 3,867 & 19,280 & 27,732 & 33,466 & 42,552 \\
\hline Part time work ${ }^{6}$ & 4,785 & 0.098 & - & - & - & - & - \\
\hline
\end{tabular}

All monetary values are expressed are expressed in constant 2013 Euros.

${ }^{1}$ Number of working days in salaried employment in quarter of exit and 4 following quarters. Excludes workers transiting first to selfemployment.

${ }^{2}$ Daily wage is the average gross wage (before taxes and personal social security contributions) in the most important salaried job in the quarter of exit to employment. Excludes 526 missing observations.

${ }^{3}$ Daily wage in quarter of exit replaced by daily wage in the following quarter if the latter deviates more than $5 \%$ from the former. This correction is applied because the daily wage is more sensitive to measurement error (possibly missing) if exit to employment occurs near the end of a quarter and, hence only observed over a short period. Excludes 245 missing observations

${ }^{5}$ In the quarter of exit and each 4 following quarters the product of the average gross daily wage in the most important job and the number of working days in salaried employment is calculated. The reported figure is the sum of these products over all quarters. Excludes 96 observations for which wage data are missing in all quarters. If the wage is missing in any of the other quarters, earnings was set to zero in the corresponding quarter.

${ }^{6}$ Indicator variable taking on the value one if a person works part time in the quarter of exit and zero otherwise.

Based on the administrative information of the BCSS, we constructed a number of additional outcomes of interest that aim at measuring potential effects of the policies on the quality of employment. We consider the number of working days in salaried employment in the quarter of exit from unemployment and the 4 subsequent quarters, the daily wage in the quarter of exit, the daily wage multiplied by the number of working days in the quarter of exit and the 4 subsequent quarters, and an indicator equal to one if a salaried worker worked part-time in the quarter of exit and zero otherwise. We only observe 
these additional variables for the individuals who transited to salaried employment, not for those who became self-employed, neither for those who did not find a job.

For the daily wage in the quarter of exit, for instance, there is a relatively large number of missing values. This may be a consequence of individuals leaving the unemployment registers near the end of the quarter while not entering employment immediately afterwards. That is why we also considered a second (corrected) daily wage in which we replace the first wage by the wage measured in the subsequent quarter if this wage deviates more than $5 \%$ from the first one and is not zero or missing.

Job seekers who find a salaried job are not all the time employed in the 5 quarters following hiring (including the quarter of hiring): 50\% works less than 270 days and one quarter less than 211 days. If we consider that in most sectors the workweek lasts 5 days and that an individual enters on average in the middle of a quarter, then someone who would have worked full-time during these 4.5 quarters would have worked 292.5 days. This corresponds roughly to the number of working days of the individual at the 75th percentile, who worked 295 days. Since only about 10\% of the hired individuals worked part-time, there is a substantial share of individuals who have lost their job within 5 quarters. The median daily gross wage is about $€ 105$ which means if, as is common for a full-time occupation in Belgium, 7.2 hours per day is worked, that the gross wage per hour (before taxes and Social Security contributions) would be about 14.6€/hour. Considering that some individuals work part-time, this is a lower bound. Finally, we measure the earnings as the sum over the aforementioned 5 quarters of the product of the average gross daily wage and the number of working days in each quarter. The median individual earned $€ 27,732$ in this period. This is about $€ 2,054 /$ month.

\section{The Empirical Approach}

The empirical analysis aims at identifying the effect of an extension of the waiting period from 9 to 12 months for school-leavers slightly younger than 26 on the various outcome variables described in the previous section. Identification is based on the discontinuity of the length of the waiting period at the age of 26 prior to 2012. Since the YWP entails another age discontinuity at 25 years and 8 months, the analysis requires to simultaneously take these two age discontinuities into account. The forcing variable $A_{i}$ is the age of individual $(i=1,2, \ldots N)$ 
9 months after the first registration of school-leavers as job seeker in the Regional $\mathrm{PES}^{7}$ measured in days and in deviation from the age discontinuity at 26 years. Let $D_{W i} \equiv 1\left[A_{i} \geq 0\right]$ denote the treatment status (extension of the waiting period from 9 to 12 months) of individual $i$ where $1[$.$] is the indicator function, D_{Y W P}$ is an indicator if the individual is younger than 25 years and 8 months (and hence eligible to the YWP) and zero otherwise, ${ }^{8} \boldsymbol{X}_{i}$ the vector of explanatory variables listed in Table $1,{ }^{9}$ and $F\left(A_{i}\right)$ and $F_{1}\left(A_{i}\right)$ two polynomial functions, assumed to be linear in the benchmark models. The following log-linear regression equation then identifies the proportional treatment effect $\beta_{W}$ of the extension of the waiting period and $\beta_{Y W P}$ for the YWP:

$$
\log \left(Y_{i}\right)=\alpha+\beta_{W} D_{W i}+\beta_{Y W P} D_{Y W P i}+F\left(A_{i}\right)+D_{i} F_{1}\left(A_{i}\right)+\boldsymbol{X}_{i} \boldsymbol{\gamma}+U_{\boldsymbol{i}}
$$

where in the benchmark models $Y_{i}$ is one of the outcome variables listed in Table $2^{10}$ and $U_{i}$ the error term. In regression specification (1) we implicitly impose the same (linear) polynomial to the left and to the right of the age cut-off for the YWP. This assumption is made, because this cut-off at 25 years and 8 months is very close to 26 years, so that a different polynomial between these two cut-offs would be identified on very few data points only. Moreover, based on the graphical analysis reported below, this assumption does not seem to be violated. Nevertheless, in a sensitivity analysis we will test this assumption, although only for the outcome for which we find a statistically significant treatment effect. We will also check for this outcome whether the results are sensitive to the age window and the choice of the polynomial function (Section 6.4).

In case the outcome variable is a duration, then for some individuals this duration is bound to terminate after the end of the observation period, or exits to a particular destination (e.g. employment) are not observed, because an exit to another destination (e.g. to inactivity) precedes exit to the destination of interest. These are instances of right censoring. Because the number of right censoring is very limited (see Table 2), we first ignore the right censored observations and run regression equation (1). Subsequently, in a sensitivity analysis, we treat

\footnotetext{
${ }^{7}$ Nine months after August 1 if registration is in July (see Section 2.1).

${ }^{8}$ Since the YWP was not yet implemented for the high-educated in 2008 , this indicator also zero for individuals of any age in 2008.

${ }^{9}$ In the benchmark analyses the equivalent household income is not included as explanatory variable.

${ }^{10}$ Since the data are left truncated at the end of the first month, we normalize the duration by subtracting one.
} 
right censored observations correctly by estimating the discrete duration model as a sequence of monthly binary choices (Kiefer 1988; Jenkins 1995). ${ }^{11}$

Let $t \in\{2,3, \ldots\}$ and $\epsilon_{i}$ denote the elapsed unemployment duration and the unobserved determinants of the exit rate from unemployment for individual $i$, respectively. ${ }^{12}$ We assume that these unobserved determinants are independently distributed from the observed covariates. This allows to take the dynamic selective sorting of the pool of unemployed individuals over the course of the unemployment spell into account (Salant 1977). The conditional discrete-time hazards $h\left(t ; A_{i}, \boldsymbol{X}_{i}, \epsilon_{i}\right) \equiv P\left(T_{i}=t \mid T_{i} \geq t ; A_{i}, \boldsymbol{X}_{i}, \epsilon_{i}\right)$ associated to these binary choices take on the complementary log-log specification if they are derived from a continuous time hazard model:

$$
h\left(t ; A_{i}, \boldsymbol{X}_{i}, \epsilon_{i}\right)=1-\exp \left[-\exp \left(\alpha_{t}+\beta_{W t} D_{W i}+\beta_{Y W P} D_{Y W P i}+F\left(A_{i}\right)+D_{i} F_{1}\left(A_{i}\right)+\boldsymbol{X}_{i} \boldsymbol{\gamma}+\epsilon_{i}\right)\right](2)
$$

where $\exp \left(\alpha_{t}\right)$ is the baseline hazard, $\exp \left(\beta_{W t}\right)$ and $\exp \left(\beta_{Y W P}\right)$ are the proportional treatment effect on the hazard of, respectively, the extension of the waiting period and the YWP. We consider only linear polynomials in the empirical analysis. The discrete baseline is assumed to be constant within the following sets of discrete duration months: $\{3,4\},\{5,6\},\{7,8,9\}$, $\{10,11,12\},\{13,14, \ldots\}$. The treatment effect of the extension of the waiting period is assumed to be either fixed over the complete unemployment spell $\left(\beta_{W t}=\beta_{W}\right)$ or piecewise-constant over the following sets of months: $\{2,3,4,5,6,7,8,9\},\{10,11,12\}$ and $\{13,14, \ldots\}$. The latter specification aims at testing whether there are differential effects of the extension of the waiting period over the course of the unemployment spell, as predicted by standard non-stationary job search theory (Section 3). We maintain the assumption of a constant treatment effect of the YWP, because the sample size is too small to allow for time-varying effects.

This model is estimated by maximum likelihood. To form the likelihood function, note that the discrete survival rate after an elapsed duration of $t$ months is simply the product of one minus the discrete-time hazards in all preceding periods: $\prod_{s=2}^{t}\left(1-h\left(s ; A_{i}, \boldsymbol{X}_{i}, \epsilon_{i}\right)\right)$. Consequently, if $c_{i}$ denotes an indicator that is equal to zero in case of right censoring and one otherwise, then the log-likelihood function, from which the unobserved determinants are integrated out, can be written as follows:

\footnotetext{
${ }^{11}$ See Lammers et al. (2013) for a similar treatment of RDD within a hazard modeling framework.

${ }^{12}$ Recall that because of left truncation the first exit can be observed from the second month only.
} 


$$
\log \mathcal{L}=\sum_{i=1}^{N} \log \left[\int_{-\infty}^{+\infty}\left[h\left(t_{i} ; A_{i}, \boldsymbol{X}_{i}, \epsilon_{i}\right)\right]^{c_{i}} \prod_{s=2}^{t_{i}-1}\left(1-h\left(s ; A_{i}, \boldsymbol{X}_{i}, \epsilon_{i}\right)\right) d G\left(\epsilon_{i}\right)\right]
$$

where $G\left(\epsilon_{i}\right)$ is the distribution of unobserved heterogeneity. We perform estimations in which we either assume that there is no unobserved heterogeneity or that it is Normally distributed with mean zero and variance $\sigma^{2}$.

Figure 2: UI Benefit Receipt at Various Unemployment Durations by Age

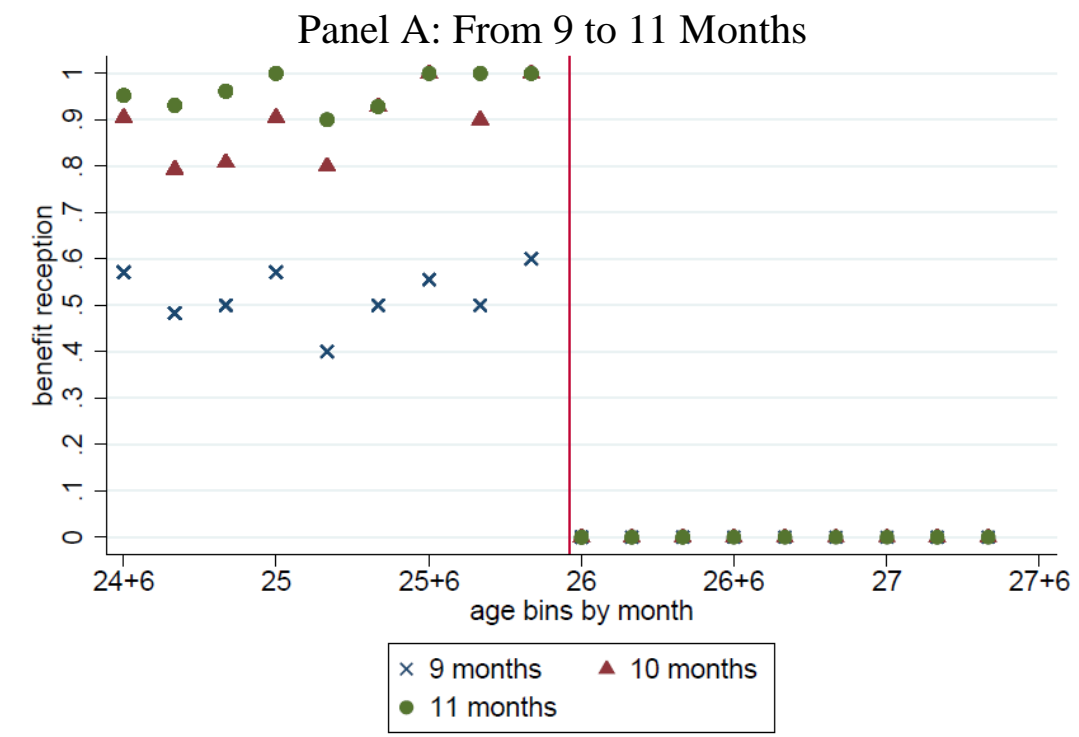

Panel B: After 12 or 13 Months

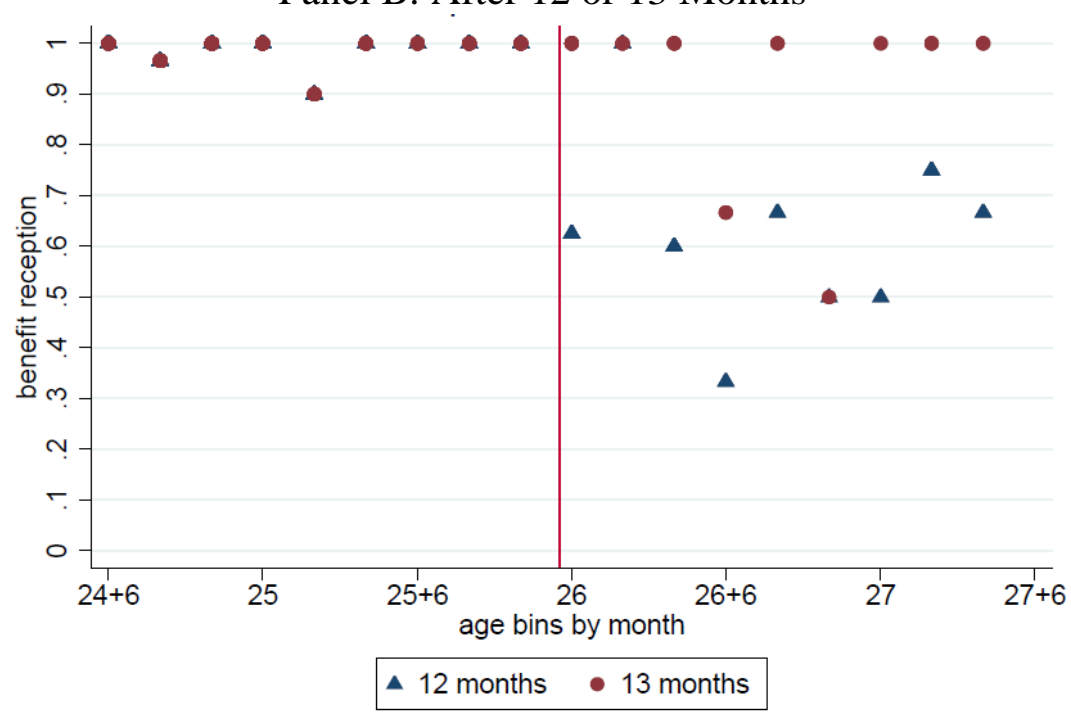

\section{The Empirical Findings}

6.1 Discontinuities in the Timing of Benefit Receipt and in the Participation in the YWP

Figure 2 displays how UI benefit receipt varies over age at various unemployment durations. 
By construction nobody is entitled to UI before 9 months. Let us first consider panel A. From 9 months the benefit receipt rate jumps up for those younger than 26 to 40-60\%, depending on the specific age. Not everyone is entitled, because of slight measurement errors, in particular potentially due to brief interruptions of inactivity (see previous section). Compatible with this interpretation, the receipt rate increases further to more than $80 \%$ after 10 months and to 90 $100 \%$ in month 11 . For those older than 26 a similar pattern is observed after 12 months (Panel B). The benefit receipt rates are more unstable for this group, but this is a consequence of the small numbers involved: only 5\% on average are unemployed for 12 months or more (Table 2) and the sample size of the older group is much smaller. We can conclude that there is a clear discontinuity in the waiting period before entitlement to UI at the age of 26. Even if, as a consequence of measurement error, the RDD is not completely sharp and the treatment effects must be, hence, interpreted as "intention-to-treat" effects, we therefore expect that if the differential waiting period has an impact on job search behaviour, this should show up in a discontinuity in the unemployment duration and, possibly, in the selected indicators of employment quality.

Figure 3: Evolution of the Fraction Labelled in the YWP by Age

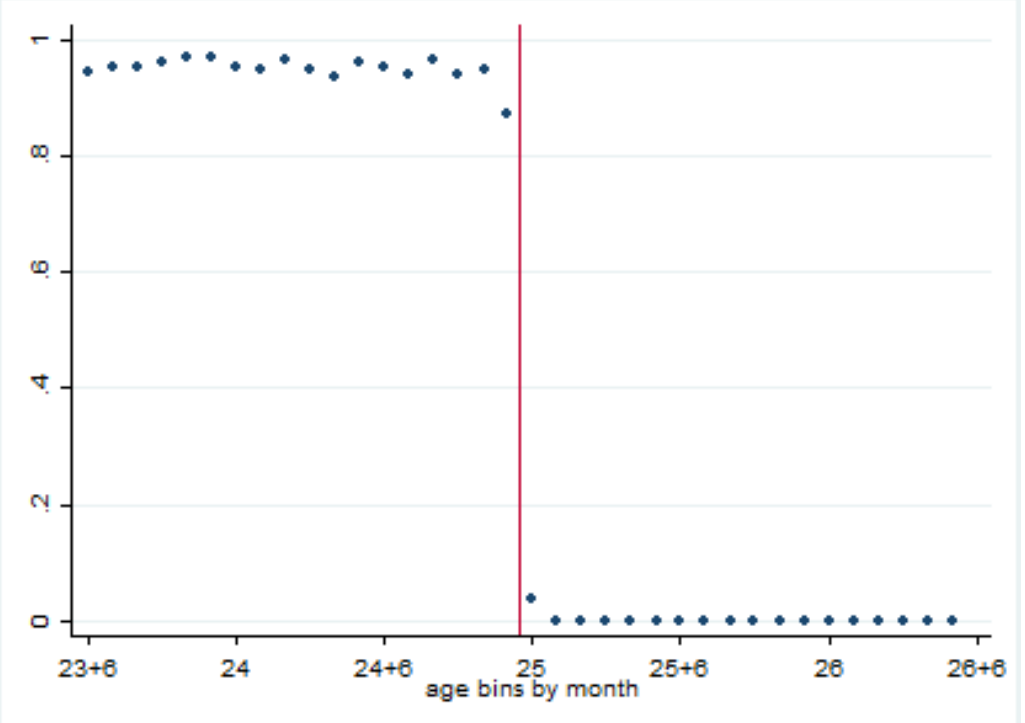

Figure 3 displays the evolution of fraction of individuals that are labelled in the YWP by age, as measured one month after the registration as job seeker. ${ }^{13}$ The fraction labelled drops sharply

\footnotetext{
${ }^{13}$ Note that this analysis is based on a larger dataset, since the participation indicator to the YWP is not available in the dataset that was matched to the BCSS. Hence, we could not exclude individuals who experienced employment prior to registration as job seeker, neither could we exclude individuals who were entitled to UI prior to the end of the waiting period and, hence, could not be school-leavers. Individuals who registered in 2008 are excluded from this analysis, because the YWP was then not yet implemented for the high-educated.
} 
at the age of 25. This justifies the inclusion of a second discontinuity point in the analysis at 25 years and 8 months, if age is measured at the potential start of benefit receipt, i.e. 9 months after registration as job seeker.

\subsection{The Effects on Unemployment Duration}

Figure 4 displays the unemployment duration as a function of age where dots represent the averages by age bins of 2 months. As mentioned in the section describing the data, older schoolleavers are more likely to have repeated grades and are, hence, less attractive for potential employers. This is reflected in an increasing relationship of unemployment duration with age. However, despite the clear discontinuity in benefit receipt at age 26 and of participation in the YWP at 25 years and 8 months, the unemployment duration only drops slightly at 26 and evolves very smoothly at 25 years and 8 months. This means that benefit extension seems to have only a slight impact on job search behaviour, if any, while the YWP not at all.

Figure 4: Unemployment Duration by Age

(age bins by 2 months)

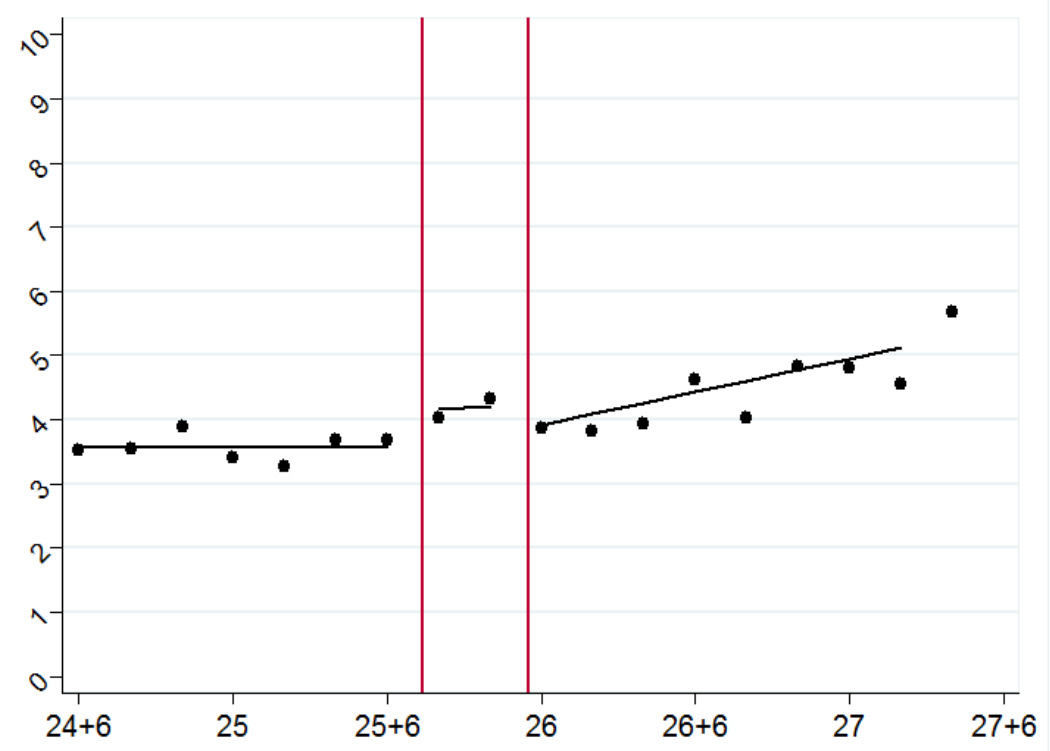

Note: $0.24 \%$ of the full sample are right censored observations and, hence, dropped.

The graphical evidence is quite salient. The formal econometric analysis just confirms this evidence. Table 3 summarize the findings of the econometric estimations of the linear regression and the discrete hazard model. In all of them the polynomial in age is specified as a linear spline. The first four columns of the first row report the estimated bench mark treatment effects (and associated standard errors) of the extension of the waiting period $\left(\hat{\beta}_{W}\right)$ and of the YWP $\left(\hat{\beta}_{Y W P}\right)$ obtained by estimating the linear regression. The first two columns consider the 
(log) unemployment duration to any exit destination, while in the two subsequent columns the analysis is restricted to (log) durations ending in employment. In the first analysis 12 individuals are right censored at the end of the observation period and in the second, in addition, 396 observations with exits to inactivity are excluded from this analysis. The last two columns of Table 3 presents the results of interest for the discrete hazard model. The coefficients are reported in exponential form, so that they can be interpreted as multipliers of the hazard. In column (5) we report the findings of the model that assumes a constant proportional treatment effect throughout the unemployment spell. Column (6) shows the results for the model that allows a different treatment effect of the extension of the waiting period in months 2 to 8,9 to 12 and beyond 12 months.

Table 3: Estimation Results for Unemployment Duration and Transitions to Employment as Outcomes of Interest

\begin{tabular}{|c|c|c|c|c|c|c|c|}
\hline \multirow[b]{2}{*}{ Coef. } & \multicolumn{2}{|c|}{ Any Exit } & \multicolumn{5}{|c|}{ Exit to employment } \\
\hline & $\begin{array}{c}(1) \\
\text { Linear }\end{array}$ & $\begin{array}{c}(2) \\
\text { Log-linear }\end{array}$ & $\begin{array}{c}\text { (3) } \\
\text { Linear }\end{array}$ & $\begin{array}{c}(4) \\
\text { Log- } \\
\text { linear }\end{array}$ & Exp. (Coef.) & $\begin{array}{c}(5) \\
\text { Hazard }\end{array}$ & $\begin{array}{c}(6) \\
\text { Hazard }\end{array}$ \\
\hline \multirow[t]{4}{*}{$\boldsymbol{\beta}_{W}$} & $\begin{array}{c}-0.126 \\
(0.283)\end{array}$ & $\begin{array}{c}-0.011 \\
(0.049)\end{array}$ & $\begin{array}{c}-0.156 \\
(0.293)\end{array}$ & $\begin{array}{c}-0.012 \\
(0.051)\end{array}$ & $\exp \left(\beta_{W}\right)$ & $\begin{array}{c}1.044 \\
(0.088)\end{array}$ & - \\
\hline & - & - & - & - & $\exp \left(\beta_{W 2-9}\right)$ & - & $\begin{array}{c}1.047 \\
(0.088)\end{array}$ \\
\hline & - & - & - & - & $\exp \left(\beta_{W 10-12}\right)$ & - & $\begin{array}{c}0.921 \\
(0.183)\end{array}$ \\
\hline & - & - & - & - & $\exp \left(\beta_{W 13-\infty}\right)$ & - & $\begin{array}{c}1.180 \\
(0.232)\end{array}$ \\
\hline \multirow[t]{2}{*}{$\beta_{Y W P}$} & $\begin{array}{c}0.122 \\
(0.243)\end{array}$ & $\begin{array}{c}0.003 \\
(0.041)\end{array}$ & $\begin{array}{c}0.049 \\
(0.246)\end{array}$ & $\begin{array}{c}-0.001 \\
(0.042)\end{array}$ & $\exp \left(\beta_{Y W P}\right)$ & $\begin{array}{c}0.953 \\
(0.067)\end{array}$ & $\begin{array}{c}0.953 \\
(0.066)\end{array}$ \\
\hline & & & & & $\begin{array}{l}\text { Variance } \\
\text { heterogeneity }\end{array}$ & $\begin{array}{c}0.635^{* * *}(0 \\
082)\end{array}$ & $\begin{array}{c}0.631^{* * *} \\
(0.082)\end{array}$ \\
\hline$N$ & 5,483 & 5,483 & 5,087 & 5,087 & $N$ & 5,495 & 5,495 \\
\hline$R^{2}$ & 0.043 & 0.047 & 0.041 & 0.047 & log-likelihood & -11338.2 & -11337.6 \\
\hline
\end{tabular}

Notes: Heteroskedastic robust standard errors between parentheses. All models include the control variables mentioned in Table 1 (except for the equivalent household income) and a linear spline in age. In the (log-) linear models right-censored observations are dropped: 12 observations in case of exits to any destination reported in the first two columns; an additional 396 individuals who leave from unemployment to inactivity in case duration until exit to employment is considered. In the hazard models the aforementioned dropped observations are right censored. "Variance heterogeneity" is the variance of the Normal mixing distribution of the unobserved heterogeneity. ${ }^{*}$ p-value less than $10 \%,{ }^{* *}$ p-value less than $5 \%$, ${ }^{* * *}$ p-value less than $1 \%$.

In line with expectations of job search theory, the extension of the waiting period is found to decrease unemployment duration. However, the extension by 3 months reduces the unemployment duration of a 26 year old job seeker by 0.13 months (column (1)) or 1.1\% (column (2)) only, and is not statistically different from zero. The effect of the YWP is positive for both the linear and the log-linear model and even closer to zero than the effects of an extension of the waiting period. In Appendix B we present the complete estimation results of 
these benchmark models.

The third (and fourth) column presents the results of the same model in which we replace the outcome of interest by the (log-) unemployment duration ending in a transition to employment. The findings hardly alter, because only very few job seekers leave unemployment to inactivity (just 396 out of 5,483). The discrete hazard model in column (5) that allows for a correct treatment of right censoring and exits to inactivity displays slightly larger proportional effect of the extension on the hazard $(+4.4 \%)$ and a small negative effect of the YWP $(-4.7 \%=(1-$ 0.953)*100), but these effects are again not statistically significant. Finally, the findings reported in column (6) shows some non-monotonic variation of the extension of the waiting period in the considered sub-periods, but the treatment effects are never significantly different from one. This insignificance could be the consequence of lack of precision induced by the double age discontinuity, one at 25 years and 8 months and one at 26 years. Before providing any interpretation of these potential treatment effects we consider their effects on some indicators of quality of employment.

\subsection{The Effects on the Quality of Employment}

Figure 5 displays the evolution over age of various indicators of the quality of employment: the log number of working days in the quarter of exit and the 4 subsequent quarters, the fraction of individuals working part-time, the (possibly corrected) log daily wage at the end of the quarter of exit, the log of annual earnings in the quarter of exit and the 4 subsequent quarters. The daily wage (corrected or not) and the indicator of part-time work evolve very smoothly at the two age discontinuities, providing evidence that these outcomes are not influenced by the policies. For the number of working days and the earnings the age bin at 25 years and 10/11 months displays a spike, while at 25 and 8/9 months there is no discontinuity at all compared to the earlier ages to the left, i.e. the age discontinuity point of the YWP. The spike at age 25 and 10/11 months occurs at an instant that neither the extension of the waiting period nor the YWP is in operation. This suggests that both policies affect the aforementioned outcomes negatively. ${ }^{14}$ The lack of discontinuity at the age discontinuity of the YWP (at 25 years and 8/9 months) suggests nevertheless that part of the spike is generated by chance. Observe, however, that the graph is only compatible with the absence of any impact of the YWP if the underlying slope of the relationship between age and outcomes would dramatically change between the

\footnotetext{
${ }^{14}$ Note that it is unlikely that this spike just reflects lack of statistical precision due to too small bin size. This becomes an issue only from age 26.5 onwards, because very few individuals graduate and register as unemployed at those ages. Before age 26.5 the average outcome is fairly stable by bin, except for the aforementioned spike.
} 
two age discontinuities, i.e. would become upward sloping (as the two bins seem to suggest). By contrast, if we impose this slope to correspond to the one determined to the left of the age thresholds (as in the figure), then the YWP clearly affects the outcomes negatively: The predicted days worked and earnings of younger individuals to the left of the YWP-discontinuity are clearly lower than those of the older individuals to the right. This is also the robust conclusion of the formal econometric analysis below.

Figure 5: Indicators of Quality of Employment by Age

(age bins by 2 months)
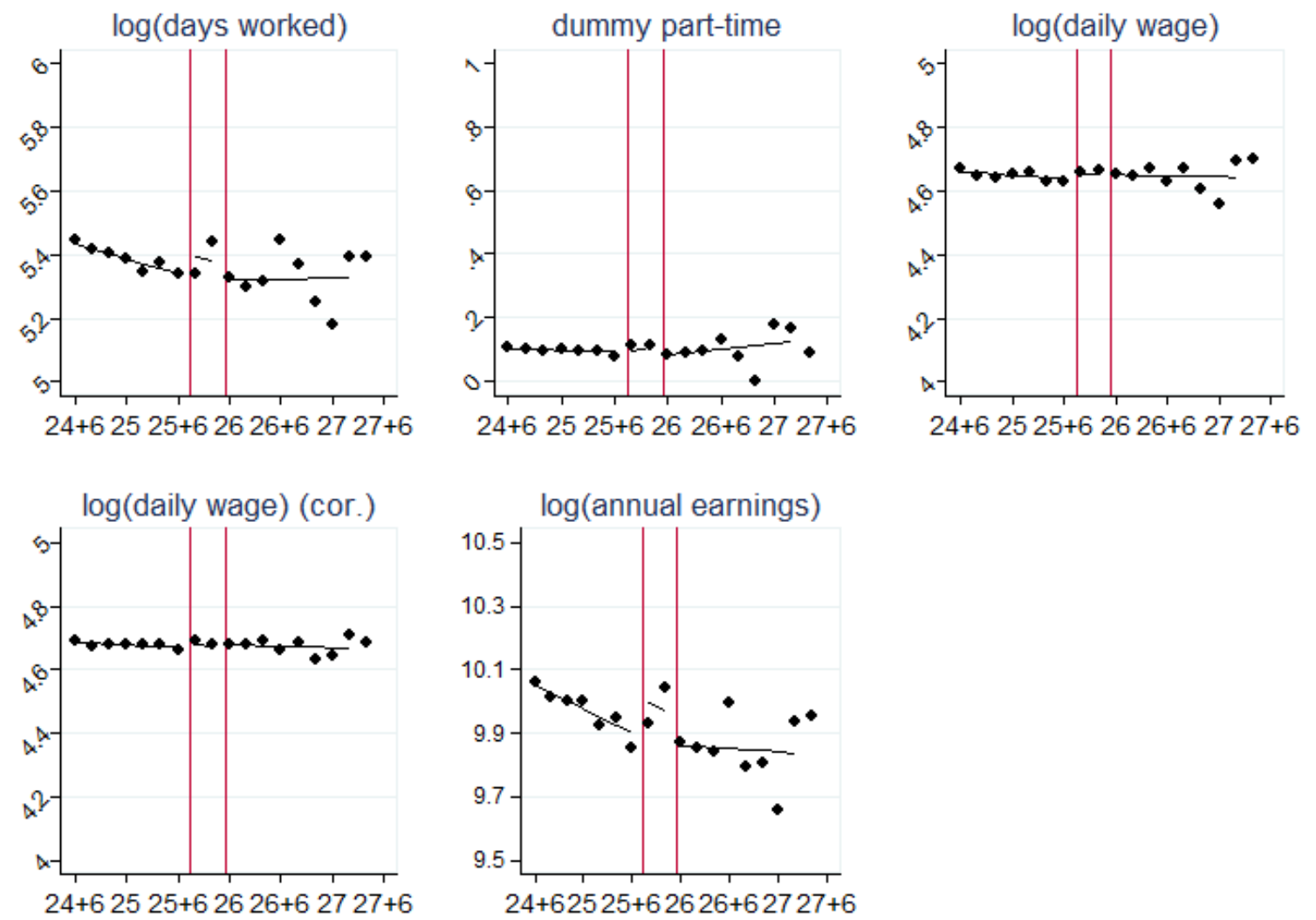

Table 4 presents, based on the linear regression model (1), the formal econometric estimates of the parameters of interest for the aforementioned outcomes. Since these outcomes are only measured for individuals in salaried employment for whom there is no missing value in the registers, we first check whether we should not be concerned by a sample selectivity at the age discontinuity points of interest (Heckman 1974). We therefore first ran a linear probability model specified as in equation (1), where the dependent variable is equal to one if the considered outcome has a non-missing value and is equal to zero otherwise. From these regressions we conclude that there is only a major concern for the non-corrected daily wage, but not for the 
corrected daily wage. Furthermore, we plotted for each of the retained samples of each of the considered outcomes, the evolution of each of the explanatory variables against age and did not find evidence of any clear discontinuities. ${ }^{15}$ The outcomes of these tests are comforting, but no formal proof of the absence of sample selectivity at the age discontinuities.

Table 4: Estimation Results on Employment Quality and Associated Selection Indicators

\begin{tabular}{|c|c|c|c|c|c|c|}
\hline & \multicolumn{2}{|c|}{ Days worked } & \multicolumn{2}{|c|}{ Dummy part time } & \multicolumn{2}{|c|}{ Daily wage } \\
\hline Coef. & Select D & Log-lin. & \multicolumn{2}{|c|}{ Lin. } & Select D & Log-lin. \\
\hline$\widehat{\boldsymbol{\beta}}_{W}$ & $\begin{array}{l}-0.027 \\
(0.018)\end{array}$ & $\begin{array}{l}-0.035 \\
(0.047)\end{array}$ & \multicolumn{2}{|c|}{$\begin{array}{l}-0.023 \\
(0.019)\end{array}$} & $\begin{array}{c}-0.071^{* *} \\
(0.027)\end{array}$ & $\begin{array}{l}0.003 \\
(0.015)\end{array}$ \\
\hline$\widehat{\beta}_{Y W P}$ & $\begin{array}{l}-0.006 \\
(0.014)\end{array}$ & $\begin{array}{l}-0.068 * \\
(0.039)\end{array}$ & \multicolumn{2}{|c|}{$\begin{array}{l}-0.008 \\
(0.016)\end{array}$} & $\begin{array}{l}-0.044^{*} \\
(0.022)\end{array}$ & $\begin{array}{l}-0.010 \\
(0.012)\end{array}$ \\
\hline$N$ & 5,495 & 4,785 & \multicolumn{2}{|c|}{4,785} & 5,495 & 4,259 \\
\hline$R^{2}$ & 0.017 & 0.024 & \multicolumn{2}{|c|}{0.053} & 0.018 & 0.075 \\
\hline & \multicolumn{2}{|c|}{$\begin{array}{l}\text { Daily wage } \\
\text { (corrected) }\end{array}$} & \multicolumn{2}{|c|}{ Earnings } & & \\
\hline Coef. & Select D & Log-lin. & Select D & Log-lin. & & \\
\hline$\widehat{\boldsymbol{\beta}}_{W}$ & $\begin{array}{l}-0.037 \\
(0.024)\end{array}$ & $\begin{array}{c}0.004 \\
(0.014)\end{array}$ & $\begin{array}{c}-0.032 \\
(0.020)\end{array}$ & $\begin{array}{c}-0.055 \\
(0.063)\end{array}$ & & \\
\hline$\widehat{\beta}_{Y W P}$ & $\begin{array}{l}-0.026 \\
(0.019)\end{array}$ & $\begin{array}{l}-0.005 \\
(0.011)\end{array}$ & $\begin{array}{l}-0.015 \\
(0.016)\end{array}$ & $\begin{array}{l}-0.054 \\
(0.051)\end{array}$ & & \\
\hline$N$ & 5,495 & 4,540 & 5,495 & 4,689 & & \\
\hline$R^{2}$ & 0.020 & 0.072 & 0.022 & 0.036 & & \\
\hline
\end{tabular}

Notes: Heteroskedastic robust standard errors between parentheses. All models include control variables mentioned in Table 1 (apart from the equivalent household income) and a linear spline in age. Select $D$ refers to an indicator that is equal to one if the associated outcome is observed and zero if it is missing. It therefore refers to a linear probability regression based on Equation (1) that aims at identifying whether there is any sample selectivity at the age discontinuity of 26. Log-lin. Refers to a log-linear regression of the associated indicator of employment quality based on equation (1). ${ }^{*} \mathrm{p}$-value less than $10 \%,{ }^{* *} \mathrm{p}$-value less than $5 \%,{ }^{* * *} \mathrm{p}$-value less than $1 \%$.

In line with the graphical evidence, both policies have a small and statistically insignificant effect on the gross wage and on part-time employment. Both the YWP and the extension of the waiting period by three months are found to have a negative impact on hours worked and on earnings, although not statistically significant at the $5 \%$ level: the former reduces working time by $6.8 \%$ (p-value of $8.3 \%$ ) and earnings by $5.4 \%$, while for the latter these effects are $-3.5 \%$ and $-5.5 \%$, respectively.

Because the effects on working days and earnings were barely statistically significant, we performed a couple of sensitivity analyses on these variables. We considered (1) a narrower window around the age discontinuity at 26, (2) a spline at the age discontinuity of 25 and 8 months rather than at the one at 26, (3) a linear and (4) quadratic function of age without spline. These findings are reported in Appendix C. Even if the effects remain statistically insignificant, the findings are remarkably robust, especially for the YWP. Only if we consider the spline at

\footnotetext{
${ }^{15}$ These graphs can be obtained from the authors upon request.
} 
the age discontinuity of the YWP or we do not consider any spline at all the effects of the extension of the waiting period is much smaller. For the extension of the waiting period the sign of the effect is in line with standard job search theory in that job seekers respond by lowering the job acceptance requirements, i.e. jobs with shorter expected duration are accepted. The fact that the reservation wage is not affected is probably related to the binding minimum wage for these youths. According to the point estimates of the various models this decreases earnings between 3.5\% and 7\%. Lowering job acceptance requirements should generally also lead to more job acceptance and, hence, increase the job finding rate. We found, however, much smaller effects on the job finding rate (Table 3). This suggests that the acceptance of lower quality jobs does not accelerate job finding very much.

The significant negative impact of the YWP on days worked suggests that PES caseworkers induced unemployed school-leavers to accept more temp jobs and/or fixed-term contracts then they would have done in the absence of the YWP. Caseworkers could have justified this strategy based on the argument that short-term jobs could be stepping stones to a more permanent job. However, the empirical evidence on the effectiveness of this strategy is mixed. For instance, stepping-stone effects have been found by Booth et al. (2002) in the UK, Ichino et al. (2008), de Graaf-Zijl et al. (2011) in the Netherlands and Cockx and Picchio (2012) in Belgium, while other researchers have found adverse effects, such as Güel and Petrongolo (2007) in Spain, and Autor and Houseman (2010) in the US. Givord and Wilner (2015) in a recent paper argue that these mixed findings may be a consequence of lumping together temp jobs and fixed term contracts when analyzing their effect. These authors find on French data that "although fixedterm contracts may provide a 'stepping-stone’ to permanent positions, temporary agency work is hardly better than unemployment in this regard.” The PES explicitly announces on its website its partnership with the sector of temporary work agencies and that it regards temp jobs as 'stepping stones' to regular work ${ }^{16}$. Even if we do not have hard evidence that caseworkers indeed advice youths to accept temp jobs, our findings and the aforementioned empirical evidence are consistent with this interpretation.

\subsection{Validity Tests}

We have checked for the validity of the RDD based on two standard tests. In Appendix D we present the graphical tests proposed by McCrary (2008) as to demonstrate that "manipulation”

\footnotetext{
${ }^{16}$ See vdab.be/uitzendsector/samenwerking.shtml [accessed on 13/09/2016].
} 
of the sorting variable does not threaten the validity of the RDD. In Appendix E we further justify the validity of our approach by reporting for all considered outcomes the placebo tests on the 2012 data. In 2012 the waiting period has become equally long for all age groups, so that no impact at the age threshold of 26 should be found. This is confirmed.

\subsection{Treatment Heterogeneity}

In Section 3 we argued that the extension of the waiting period might not induce that important effects on job search behaviour, because the parents might financially compensate for the income loss. The fact that more than $80 \%$ of the school-leavers lived at their parent's house at the end of the calendar year preceding their first registration as job seeker at the PES (Table 1) suggests that this might be relevant. To investigate this issue further we split the sample in two groups depending on whether the equivalent income from labour income and social security allowances of other household members was either below or above the median. We only report the results from the baseline model and for the days worked and earnings, for which we found a significant effect.

Table 6: Heterogeneous Effects by Equivalent Household Income

\begin{tabular}{|c|c|c|c|c|}
\hline & \multicolumn{2}{|c|}{ Log duration in unemployment } & \multicolumn{2}{|c|}{ Days worked } \\
\hline Coef. & Income $\leq$ median & $\begin{array}{c}\text { Income }> \\
\text { median }\end{array}$ & Income $\leq$ median & Income $>$ median \\
\hline$\widehat{\boldsymbol{\beta}}_{W}$ & $\begin{array}{c}0.018 \\
(0.071)\end{array}$ & $\begin{array}{c}-0.074 \\
(0.069)\end{array}$ & $\begin{array}{l}-0.065 \\
(0.069)\end{array}$ & $\begin{array}{c}-0.032 \\
(0.064)\end{array}$ \\
\hline$\widehat{\beta}_{Y W P}$ & $\begin{array}{c}0.003 \\
(0.061)\end{array}$ & $\begin{array}{c}0.002 \\
(0.057)\end{array}$ & $\begin{array}{c}-0.123^{* *} \\
(0.055)\end{array}$ & $\begin{array}{c}-0.032 \\
(0.057)\end{array}$ \\
\hline$N$ & 2,705 & 2,704 & 2,361 & 2,358 \\
\hline \multirow[t]{2}{*}{$\mathbf{R}^{2}$} & 0.059 & 0.045 & 0.036 & 0.023 \\
\hline & \multicolumn{2}{|c|}{ Earnings } & & \\
\hline Coef. & Income $\leq$ median & $\begin{array}{c}\text { Income }> \\
\text { median }\end{array}$ & & \\
\hline$\widehat{\boldsymbol{\beta}}_{W}$ & $\begin{array}{c}0.023 \\
(0.021)\end{array}$ & $\begin{array}{l}-0.015 \\
(0.022)\end{array}$ & & \\
\hline$\widehat{\beta}_{Y W P}$ & $\begin{array}{c}-0.003 \\
(0.017)\end{array}$ & $\begin{array}{l}-0.016 \\
(0.017)\end{array}$ & & \\
\hline $\mathbf{N}$ & 2,104 & 2,099 & & \\
\hline $\mathbf{R}^{2}$ & 0.074 & 0.081 & & \\
\hline
\end{tabular}

In the first two columns of the first panel of Table 6, we report the findings of this analysis for the benchmark outcome, i.e. log unemployment duration with exits to all destinations. For this 
outcome variable the effect of an extension of the waiting period is qualitatively the reverse of what we would have expected. The effect on unemployment duration is more negative for youths living in households with high equivalent income. Standard errors are, however, again very large, so that no firm conclusion can be drawn. The two first columns of the subsequent panel report the effects on days worked. In this case the effect goes in the expected direction. A longer waiting period induces low-income-youths to accept jobs that reduce working time by $6.5 \%$, while this reduction is only $3.2 \%$ for high-income-youths. While these effects are not significantly different from zero, the impact of the YWP for the low-income group is $-12.3 \%$ and significant at the $5 \%$ level, in contrast to the $-3.2 \%$ statistically insignificant effect for the high-income group. Unfortunately, this ordering of the effects according to income does not remain as clear if the effect on earnings (the last panel of Table 6) is considered.

\section{Conclusion}

In this research we exploited two policy discontinuities at two age cut-offs (at 26 years and 25 years and 8 months) to evaluate, by a Regression Discontinuity Design (RDD), the effects of two active labour market policies targeted to youth on the transition rate from unemployment to employment and on the quality of this employment. The first policy consisted in an extension of the waiting period from 9 to 12 months that was imposed on Belgian school-leavers before they were entitled to UI. The second was the Youth Work Plan (YWP) which aimed at providing more intensive counselling and training to young job seekers earlier on in their unemployment spell than to older job seekers. In order to avoid that the estimated treatment effect would be confounded by a wage subsidy programme targeted to low educated youth, the analysis was restricted to youths who recently graduated from a bachelor's or master's degree.

The study finds that such an extension of the waiting period slightly, but statistically insignificantly, increased the transition rate to employment. We argued that a potential explanation of this small impact could be that these youths were not much financially constrained by this extension, because most of them would still be financially dependent on their parents' income. However, we did not find supporting evidence for this hypothesis.

Another potential explanation of this weak impact could be that these youths form biased or non-rational expectations that could make them less responsive to future incentives (Spinnewijn 2015; Paserman 2008). Even if these elements could play a role, the analysis nevertheless finds that future incentives do affect job acceptance behaviour. While the extension of the waiting period did not affect the level of the accepted wage, we did find some suggestive, but robust, 
evidence that it did reduce the number of working days and, hence, earnings in the five quarters following exit from unemployment. This means that the extension of the waiting period induces young job seekers to accept short-term job offers more easily. These effects were found to be larger for youths living in poorer households where job acceptance is more guided by liquidity constraints.

The YWP did not have any significant positive impact on the exit rate from unemployment to employment. However, as for the extension of the waiting period, it did robustly reduce the number of working days by about 6-7\%, while leaving the wage unaffected. For youths living in households with below median equivalent income this working time fell even by about $12 \%$ and was significant at the $5 \%$ level. The effect on earnings was also negative, although slightly smaller and never statistically significant. An explanation for these findings is that PES caseworkers advised young unemployed graduates to accept more temp jobs and fixed-term contracts potentially arguing that these could be stepping stones to a permanent job. However, our findings point that the stepping stone hypothesis should be refuted as the number of working days within the first 5 quarters in the labour market were actually reduced.

Overall, even if the findings did not deliver many statistically significant estimates of the treatment effects, we nevertheless can formulate some policy conclusions. First, our analysis revealed that an extension of the waiting period either did not enhance much the transition rate to employment or, if it did, it did so at the cost of reduced working time and, hence, earnings. This suggests that threatening with a sanction is not the right method to activate youth and that supportive measures might work better. However, the Youth Work Plan (YWP) is precisely offering this kind of support and our analysis revealed that this approach produced very similar, if any, effects as the one that involves a financial sanction. Part of the explanation is that caseworkers might have given misleading advice that short-term or temp jobs are stepping stones to long-term employment. Another reason is that the Flemish YWP was not sufficiently intensive. As mentioned, experimental evidence in Denmark suggests that very intensive (fortnightly) meetings with caseworkers can generate significantly positive effects on the jobfinding rate.

Finally, even if the RDD approach followed in this research is generally a very convincing and powerful method to identify causal effects, we faced some limitations in the implementation of this method. We were confronted with two policies the participation in which was delineated by two sharp age cut-offs which were only 4 months apart. This sizeably reduced the width of 
the age window to detect a corresponding discontinuity in behaviour. Even if we had access to population data, the size of the population close to the age thresholds was very much reduced and hereby also the statistical power of the estimator.

\section{Acknowledgements}

We are obliged to the Flemish Public Employment Agency ("VDAB”) and Geert Degraeve, and the Cross Roads Bank of Social Security and Chris Brijs for the delivery of the data. We gratefully acknowledge financial support of the Flemish government through the "Policy Research Centre Work and Social Economy”. The views expressed are those of the authors and not of the Flemish government.

\section{Appendix}

Appendix A: Reduction of Sample Size after Imposition of Selection Criteria

The initial population consists of 151,744 individuals. We make consecutively the following selections:

- Delete individuals with the onset of unemployment at a different date than the first registration: 197 individuals (0.13\%); observations left: 151,547;

- Delete individuals entering unemployment in 2011, 2012 and 2013: 76,716 individuals (50.62\%); observations left: 74,831;

- Delete individuals with at most a secondary education degree: 43,150 individuals (57.66\%); observations left: 31,681;

- Delete individuals who have worked prior to the onset of the waiting period: 9,003 individuals (28.42\%); observations left: 22,678;

- Delete individuals finding a job according to the PES, but not found to be employed in the corresponding quarter in the social security files: 432 individuals (1.90\%); observations left: 22,246;

- Delete individuals who receive UI benefit before the end of the waiting period: 80 individuals (0.36\%); observations left: 22,166;

- $\quad$ Retain individuals within an age window of 3 years around the age discontinuity at 26 years (1.5 years to the left and to the right): 16,479 individuals deleted to the left of the discontinuity (74.34\%) and 192 individuals to the right of the discontinuity (3.38\%); observations left: 5,495.

The final sample for analysis consists of 5,495 individuals. 
Appendix B: Complete Estimation Results for the Benchmark Outcome

Unemployment duration is the benchmark outcome for our analysis. In this appendix we report the full estimation results (except for the region dummies and the year and monthly entry dummies) for both the linear regression model defined by Equation (1) and the hazard model defined by Equation (2). The full estimation results for the other outcomes can be obtained from the authors upon request.

\begin{tabular}{|c|c|c|c|c|c|}
\hline Coef. & $\begin{array}{c}(1) \\
\text { Linear }\end{array}$ & $\begin{array}{c}(2) \\
\text { Log-linear }\end{array}$ & Exp. Coef. & $\begin{array}{c}(3) \\
\text { Hazard }\end{array}$ & $\begin{array}{c}(4) \\
\text { Hazard }\end{array}$ \\
\hline \multirow[t]{4}{*}{$\boldsymbol{\beta}_{W}$} & $\begin{array}{c}-0.126 \\
(0.283)\end{array}$ & $\begin{array}{c}-0.108 \\
(0.049)\end{array}$ & $\exp \left(\beta_{W}\right)$ & $\begin{array}{c}1.040 \\
(0.083)\end{array}$ & - \\
\hline & - & - & $\exp \left(\beta_{W 2-9}\right)$ & - & $\begin{array}{c}1.044 \\
(0.084)\end{array}$ \\
\hline & - & - & $\exp \left(\beta_{W 10-12}\right)$ & - & $\begin{array}{c}0.829 \\
(0.154)\end{array}$ \\
\hline & - & - & $\exp \left(\beta_{W 13-\infty}\right)$ & - & $\begin{array}{c}1.267 \\
(0.234)\end{array}$ \\
\hline$\beta_{Y W P}$ & $\begin{array}{c}0.122 \\
(0.243)\end{array}$ & $\begin{array}{c}0.003 \\
(0.041)\end{array}$ & $\exp \left(\beta_{Y W P}\right)$ & $\begin{array}{c}0.960 \\
(0.064)\end{array}$ & $\begin{array}{c}0.959 \\
(0.063)\end{array}$ \\
\hline Age & $\begin{array}{c}0.001^{* *} \\
(0.001)\end{array}$ & $\begin{array}{c}0.001 \\
(0.001)\end{array}$ & & $\begin{array}{l}1.000 * * \\
(0.001)\end{array}$ & $\begin{array}{c}1.000^{* *} \\
(0.001)\end{array}$ \\
\hline $\begin{array}{l}\operatorname{Age}^{*} \\
\quad \beta_{W}\end{array}$ & $\begin{array}{c}0.002 \\
(0.001)\end{array}$ & $\begin{array}{c}0.001 \\
(0.001)\end{array}$ & & $\begin{array}{c}1.000 \\
(0.001)\end{array}$ & $\begin{array}{c}1.000 \\
(0.001)\end{array}$ \\
\hline Female & $\begin{array}{c}-0.737^{* * *} \\
(0.106)\end{array}$ & $\begin{array}{c}-0.152 * * * \\
(0.020)\end{array}$ & & $\begin{array}{c}1.323^{* * *} \\
(0.047)\end{array}$ & $\begin{array}{c}1.322^{* * * *} \\
(0.047)\end{array}$ \\
\hline Dutch & $\begin{array}{c}-0.789 * * \\
(0.289)\end{array}$ & $\begin{array}{c}-0.184^{* * * *} \\
(0.052)\end{array}$ & & $\begin{array}{c}1.365^{* * * *} \\
(0.116)\end{array}$ & $\begin{array}{c}1.366^{* * *} \\
(0.116)\end{array}$ \\
\hline Bel & $\begin{array}{c}-1.126^{*} \\
(0.580)\end{array}$ & $\begin{array}{c}-0.176^{*} \\
(0.091)\end{array}$ & & $\begin{array}{c}1.344^{* *} \\
(0.181)\end{array}$ & $\begin{array}{c}1.343^{* *} \\
(0.180)\end{array}$ \\
\hline $\begin{array}{l}\text { Driver's } \\
\text { license }\end{array}$ & $\begin{array}{l}-1.751 \\
(1.708)\end{array}$ & $\begin{array}{c}-0.035 \\
(0.190)\end{array}$ & & $\begin{array}{c}1.163 \\
(0.286)\end{array}$ & $\begin{array}{c}1.166 \\
(0.286)\end{array}$ \\
\hline Master & $\begin{array}{c}-0.097 \\
(0.132)\end{array}$ & $\begin{array}{c}0.029 \\
(0.024)\end{array}$ & & $\begin{array}{c}0.977 \\
(0.039)\end{array}$ & $\begin{array}{c}0.977 \\
(0.039)\end{array}$ \\
\hline \multicolumn{6}{|l|}{$\begin{array}{l}\text { Family } \\
\text { status }\end{array}$} \\
\hline - family & $\begin{array}{l}1.966^{*} \\
(1.066)\end{array}$ & $\begin{array}{c}0.291 \\
(0.198)\end{array}$ & & $\begin{array}{c}0.509 * * \\
(0.140)\end{array}$ & $\begin{array}{c}0.510 * * \\
(0.140)\end{array}$ \\
\hline - single & $\begin{array}{c}0.406 \\
(0.285)\end{array}$ & $\begin{array}{c}0.066 \\
(0.057)\end{array}$ & & $\begin{array}{c}0.878 \\
(0.093)\end{array}$ & $\begin{array}{c}0.879 \\
(0.093)\end{array}$ \\
\hline - children & $\begin{array}{c}1.041^{* * *} \\
(0.128)\end{array}$ & $\begin{array}{c}0.237 * * * \\
(0.032)\end{array}$ & & $\begin{array}{c}0.634 * * \\
(0.040)\end{array}$ & $\begin{array}{c}0.635^{* * *} \\
(0.040)\end{array}$ \\
\hline - other & $\begin{array}{c}0.437 \\
(0.324)\end{array}$ & $\begin{array}{c}0.072 \\
(0.061)\end{array}$ & & $\begin{array}{l}0.820^{*} \\
(0.090)\end{array}$ & $\begin{array}{l}0.822 * \\
(0.090)\end{array}$ \\
\hline $\begin{array}{l}\text { Region } \\
\text { dummies }\end{array}$ & YES & YES & & YES & YES \\
\hline \multirow[t]{5}{*}{$\begin{array}{l}\text { Entry } \\
\text { dummies }\end{array}$} & YES & YES & & YES & YES \\
\hline & & & $\lambda_{2-3}$ & $\begin{array}{c}2.133^{* * *} \\
(0.119)\end{array}$ & $\begin{array}{c}2.124^{* * *} \\
(0.118)\end{array}$ \\
\hline & & & $\lambda_{4-5}$ & $\begin{array}{c}2.166^{* * *} \\
(0.214)\end{array}$ & $\begin{array}{c}2.148^{* * *} \\
(0.212)\end{array}$ \\
\hline & & & $\lambda_{6-8}$ & $\begin{array}{c}2.482^{* * *} \\
(0.328)\end{array}$ & $\begin{array}{c}2.454 * * * \\
(0.324)\end{array}$ \\
\hline & & & $\lambda_{9-11}$ & $2.327^{* * *}$ & $2.419 * * *$ \\
\hline
\end{tabular}




\begin{tabular}{|l|c|c|l|c|c|}
\hline & & & $(0.393)$ & $(0.422)$ \\
\hline & & & $\lambda_{12+}$ & $1.933^{* *}$ & $1.791^{* *}$ \\
& & & $(0.419)$ & $(0.406)$ \\
\hline cst & $7.027^{* * *}$ & $1.287 * * *$ & & $0.120^{* * *}$ & $0.120^{* * *}$ \\
& $(1.847)$ & $(0.219)$ & & $(0.036)$ & $(0.036)$ \\
\hline & & & Variance & $0.588^{* * *}(0.0$ & $0.581^{* * *}$ \\
& & & heterogeneity & $76)$ & $(0.076)$ \\
\hline $\mathbf{N}$ & 5,483 & 5,483 & $N$ & 5,495 & 5,495 \\
\hline $\mathbf{R}^{\mathbf{2}}$ & 0.043 & 0.047 & log-likelihood & -11884.9 & -11883.2 \\
\hline
\end{tabular}

Notes: Heteroskedastic robust standard errors between parentheses. All models include the control variables mentioned in Table 1 (except for the equivalent household income) and a linear spline in age. In the (log-) linear models right-censored observations are dropped: 12 observations in case of exits to any destination reported in the first two columns; an additional 396 individuals who leave from unemployment to inactivity in case duration until exit to employment is considered. In the hazard models the aforementioned dropped observations are right censored. "Variance heterogeneity" is the variance of the Normal mixing distribution of the unobserved heterogeneity. ${ }^{*}$ p-value less than $10 \%,{ }^{* *}$ p-value less than $5 \%,{ }^{* * *}$ p-value less than $1 \%$.

\section{Appendix C: Sensitivity Analysis for Days Worked and Annual Earnings}

\begin{tabular}{|c|c|c|c|c|c|c|c|c|}
\hline \multirow[b]{2}{*}{ Coef. } & \multicolumn{4}{|c|}{ Days worked } & \multicolumn{4}{|c|}{ Annual earnings } \\
\hline & $\begin{array}{l}\text { (1) } \\
\text { Age } \\
\text { window }\end{array}$ & $\begin{array}{l}\text { (2) } \\
\text { Spline } \\
\text { YWP }\end{array}$ & $\begin{array}{l}\text { (3) } \\
\text { No spline }\end{array}$ & $\begin{array}{l}\text { (4) } \\
\text { Quad. } \\
\text { spline }\end{array}$ & $\begin{array}{l}\text { (5) } \\
\text { Age } \\
\text { window }\end{array}$ & $\begin{array}{l}\text { (6) } \\
\text { Spline } \\
\text { YWP }\end{array}$ & $\begin{array}{l}\text { (7) } \\
\text { No spline }\end{array}$ & $\begin{array}{l}\text { (8) } \\
\text { Quad. spline }\end{array}$ \\
\hline $\boldsymbol{\beta}_{W}$ & $\begin{array}{l}-0.054 \\
(0.054)\end{array}$ & $\begin{array}{l}0.016 \\
(0.061)\end{array}$ & $\begin{array}{l}-0.015 \\
(0.043)\end{array}$ & $\begin{array}{l}-0.045 \\
(0.047)\end{array}$ & $\begin{array}{l}-0.069 \\
(0.072)\end{array}$ & $\begin{array}{l}-0.050 \\
(0.085)\end{array}$ & $\begin{array}{l}-0.035 \\
(0.057)\end{array}$ & $\begin{array}{l}-0.070 \\
(0.064)\end{array}$ \\
\hline$\beta_{Y W P}$ & $\begin{array}{l}-0.069 \\
(0.048)\end{array}$ & $\begin{array}{l}-0.057 \\
(0.054)\end{array}$ & $\begin{array}{l}-0.058 \\
(0.038)\end{array}$ & $\begin{array}{l}-0.063 \\
(0.038)\end{array}$ & $\begin{array}{l}-0.048 \\
(0.064)\end{array}$ & $\begin{array}{l}-0.080 \\
(0.069)\end{array}$ & $\begin{array}{l}-0.044 \\
(0.050)\end{array}$ & $\begin{array}{l}-0.049 \\
(0.049)\end{array}$ \\
\hline$N$ & 2,832 & 3,213 & 4,785 & 4,785 & 2,762 & 3,156 & 4,689 & 4,689 \\
\hline$R^{2}$ & 0.023 & 0.021 & 0.024 & 0.024 & 0.035 & 0.041 & 0.036 & 0.037 \\
\hline
\end{tabular}

Notes: Heteroskedastic robust standard errors between parentheses. All models include control variables mentioned in Table 1 (apart from the equivalent household income) and a linear spline in age. All reported results are based on log-linear regressions of the associated indicator of employment quality as specified in equation (1). In columns (1) and (5) the specification is as in the benchmark, but the age window is narrowed down to 1 year to the left and right of the discontinuity at 26 years; in columns (2) and (6) the spline is set at the 25 years and 8 months (i.e. the discontinuity of the YWP) and the effect of the waiting period is captured by a dummy variable at 26 years; in columns (3) and (7) the specification is linear in age without any spline; in columns (4) and (8) the specification is quadratic in age without any spline. ${ }^{*} \mathrm{p}$-value less than $10 \%$, ${ }^{* *} \mathrm{p}$-value less than $5 \%$, ${ }^{* * *}$ p-value less than $1 \%$. 
Appendix D: Graphical Tests to Detect Manipulation of the Forcing Variable
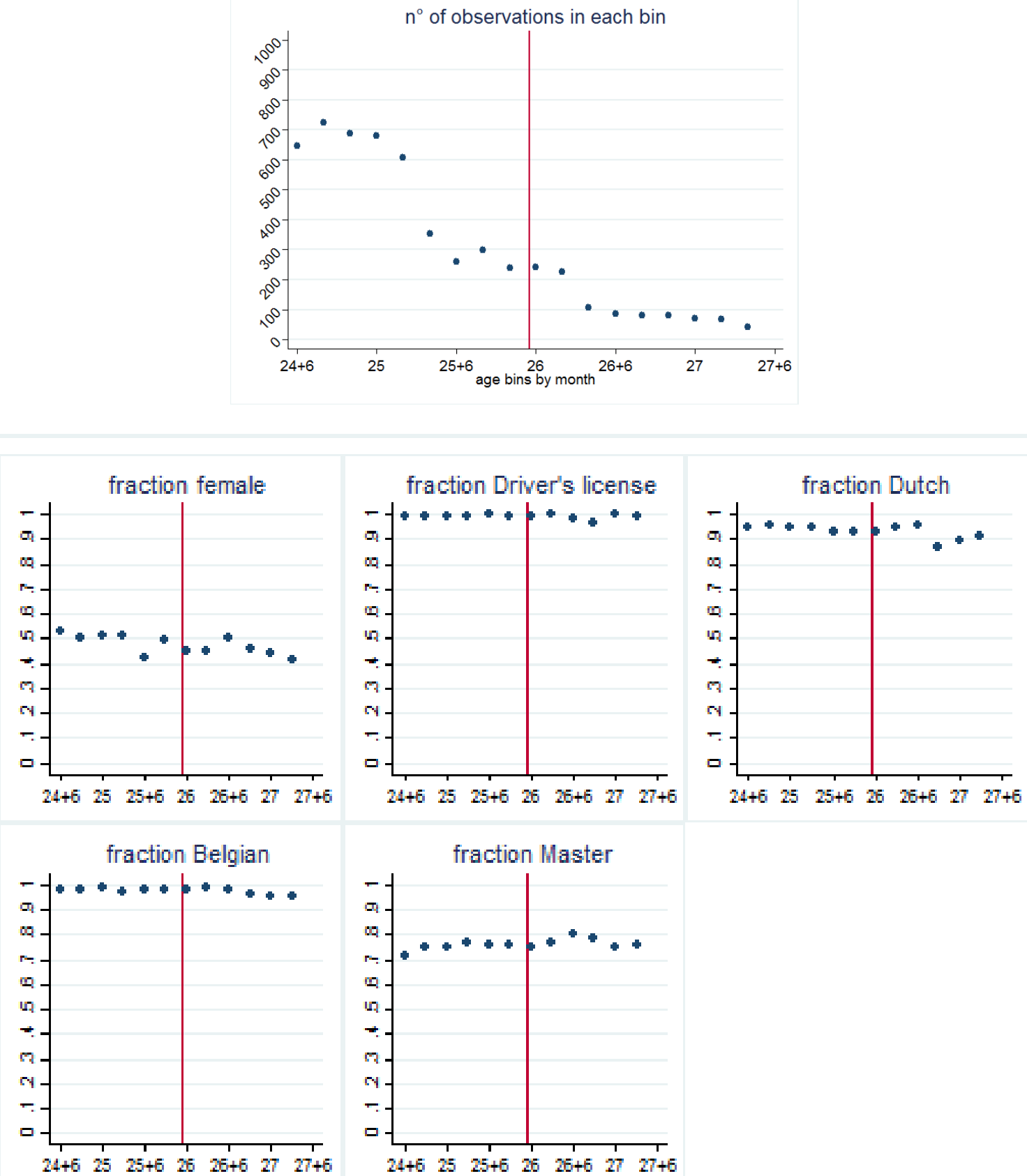
Appendix E: Placebo Test on First Registrations at the PES in 2012

\begin{tabular}{|c|c|c|c|c|c|c|c|c|c|}
\hline & \multicolumn{9}{|c|}{ Duration in unemployment } \\
\hline \multirow[b]{2}{*}{ Coef. } & \multicolumn{2}{|c|}{ Any Exit } & \multicolumn{7}{|c|}{ Exit to employment } \\
\hline & $\begin{array}{l}(1) \\
\text { Linear }\end{array}$ & $\begin{array}{c}(2) \\
\text { Log- } \\
\text { linear }\end{array}$ & $\begin{array}{l}(3) \\
\text { Linear }\end{array}$ & Log- & & Exp. Co & & $\begin{array}{l}(5) \\
\text { Hazard }\end{array}$ & $\begin{array}{c}(6) \\
\text { Hazard }\end{array}$ \\
\hline \multirow[t]{4}{*}{$\boldsymbol{\beta}_{W}$} & $\begin{array}{l}-0.058 \\
(0.424)\end{array}$ & $\begin{array}{c}0.013 \\
(0.097)\end{array}$ & $\begin{array}{c}0.220 \\
(0.426)\end{array}$ & $\begin{array}{r}0.0 \\
(0.1\end{array}$ & & $\exp \left(\beta_{W}\right.$ & & $\begin{array}{c}1.060 \\
(0.191)\end{array}$ & - \\
\hline & - & - & - & . & & $\exp \left(\beta_{W}\right.$ & & - & $\begin{array}{c}1.040 \\
(0.188)\end{array}$ \\
\hline & - & - & - & 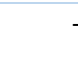 & & $\exp \left(\beta_{W}\right.$ & 12) & - & $\begin{array}{c}1.076 \\
(0.324)\end{array}$ \\
\hline & - & - & - & . & & $\exp \left(\beta_{W}\right.$ & $\infty)$ & - & $\begin{array}{c}1.679 \\
(0.569)\end{array}$ \\
\hline \multirow[t]{2}{*}{$\beta_{Y W P}$} & $\begin{array}{l}-0.589 \\
(0.389)\end{array}$ & $\begin{array}{l}-0.182 \\
(0.091)\end{array}$ & $\begin{array}{l}-0.366 \\
(0.394)\end{array}$ & $\begin{array}{l}-0.1 \\
(0.0\end{array}$ & & & & & \\
\hline & & & & & \multicolumn{3}{|c|}{$\begin{array}{l}\text { Variance } \\
\text { heterogeneity }\end{array}$} & $\begin{array}{c}0.807 * * * \\
(0.172)\end{array}$ & $\begin{array}{c}0.798 * * \\
(0.174)\end{array}$ \\
\hline$N$ & 1826 & 1826 & 1676 & \multicolumn{2}{|c|}{1676} & \multicolumn{2}{|l|}{$N$} & 1950 & 1950 \\
\hline$R^{2}$ & 0.055 & 0.069 & 0.052 & \multicolumn{2}{|c|}{0.068} & \multicolumn{2}{|c|}{ log-likelihood } & -4208.10 & -4206.90 \\
\hline \multirow[t]{2}{*}{ Coef. } & \multicolumn{2}{|c|}{$\begin{array}{c}(7) \\
\text { Days worked }\end{array}$} & \multicolumn{2}{|c|}{$\begin{array}{c}\text { (8) } \\
\text { Dummy parttime }\end{array}$} & \multicolumn{2}{|c|}{$\begin{array}{c}\text { (9) } \\
\text { Daily wage }\end{array}$} & $\begin{array}{c}(10) \\
\text { Daily wage } \\
\text { (cor.) }\end{array}$ & \multicolumn{2}{|c|}{$\begin{array}{c}\text { (6) } \\
\text { Annual earnings }\end{array}$} \\
\hline & \multicolumn{9}{|c|}{ Exit to employment } \\
\hline $\boldsymbol{\beta}_{W}$ & \multicolumn{2}{|c|}{$\begin{array}{c}0.163 \\
(0.106)\end{array}$} & \multicolumn{2}{|c|}{$\begin{array}{c}0.028 \\
(0.041)\end{array}$} & & $\begin{array}{c}0.018 \\
(0.027)\end{array}$ & $\begin{array}{c}0.035 \\
(0.027)\end{array}$ & \multicolumn{2}{|c|}{$\begin{array}{c}0.074 \\
(0.134)\end{array}$} \\
\hline$\beta_{Y W P}$ & \multicolumn{2}{|c|}{$\begin{array}{c}0.064 \\
(0.098)\end{array}$} & \multicolumn{2}{|c|}{$\begin{array}{l}-0.039 \\
(0.038)\end{array}$} & & $\begin{array}{c}0.034 \\
(0.025)\end{array}$ & $\begin{array}{c}0.031 \\
(0.024)\end{array}$ & \multicolumn{2}{|c|}{$\begin{array}{c}0.052 \\
(0.126)\end{array}$} \\
\hline$N$ & \multicolumn{2}{|c|}{1585} & \multicolumn{2}{|c|}{1585} & & 1451 & 1515 & \multicolumn{2}{|c|}{1546} \\
\hline$R^{2}$ & \multicolumn{2}{|c|}{0.059} & \multicolumn{2}{|c|}{0.065} & & 0.091 & 0.081 & \multicolumn{2}{|c|}{0.077} \\
\hline
\end{tabular}

Notes: Heteroskedastic robust standard errors between parentheses. All models include the control variables mentioned in Table 1 (except for the equivalent household income) and a linear spline in age. In the (log-) linear models right-censored observations are dropped: 12 observations in case of exits to any destination reported in the first two columns; an additional 396 individuals who leave from unemployment to inactivity in case duration until exit to employment is considered. In the hazard models the aforementioned dropped observations are right censored. "Variance heterogeneity" is the variance of the Normal mixing distribution of the unobserved heterogeneity. ${ }^{*}$ p-value less than $10 \%,{ }^{* *}$ p-value less than $5 \%,{ }^{* * *}$ p-value less than $1 \%$. 


\section{References}

Autor D. and S. Houseman (2010). "Do temporary help jobs improve labor market outcomes for low-skilled workers? Evidence from random assignments”. American Economic Journal: Applied Economics 2, 96-128.

Boone J. and J.C. van Ours (2012). "Why is There a Spike in the Job Finding Rate at Benefit Exhaustion?”. De Economist 160(4), 413-438.

Booth A., M. Francesconi and J. Frank (2002). “Temporary jobs: stepping stones or dead ends?”. In: Economic Journal 112, 189-213.

Card D., R. Chetty and A. Weber (2007). "The spike at benefit exhaustion. Leaving the unemployment system or starting a new job?”. American Economic Review 97(2), 113118.

Cockx, B. and M. Picchio (2012). "Are Short-lived Jobs Stepping-Stones to Long-Lasting Jobs”. Oxford Bulletin of Economics and Statistics 74(5), 646-675.

de Graaf-Zijl M., G. van den Berg, A. Heyma (2011). "Stepping stones for the unemployed: the effect of temporary jobs on the duration until (regular) work". Journal of Population Economics 24, 107-139.

Della Vigna, S., and M.D. Paserman (2005). "Job Search and Impatience”. Journal of Labor Economics 23, pp. 527-588.

Fredriksson P. and B. Holmlund (2006). "Improving Incentives in Unemployment Insurance: A Review of Recent Research”. Journal of Economic Surveys 20(3), 357-386.

Givord, P. and L. Wilner (2015). "When Does the Stepping-Stone Work? Fixed-Term Contracts versus Temporary Agency Work in Changing Economic Conditions.” Journal of Applied Econometrics 30, 787-805.

Güell M. and B. Petrongolo (2007). "How binding are legal limits? Transitions from temporary to permanent work in Spain”. Labour Economics 14, 153-183.

Graversen B.K. and J.C. van Ours (2008).”How to help unemployed to find jobs quickly: Experimental evidence from a mandatory activation program". Journal of Public Economics 92, 2020-2035.

Heckman, J.J. (1974). “Shadow Prices, Market Wages, and Labor Supply”. Journal of Econometrics 42(4), 679-694.

Ichino A, F. Mealli, T. Nannicini (2008). "From temporary help jobs to permanent employment: what can we learn from matching estimators and their sensitivity?”. Journal of Applied Econometrics 23, 305-327.

Imbens, G.W. and T. Lemieux (2008). "Regression discontinuity de- signs: A guide to practice”. Journal of Econometrics 142(2), 615- 635.

Jenkins, S.P. (1995). “Easy Estimation Methods for Discrete-Time Duration Models”. Oxford 
Bulletin of Economics and Statistics 57(1), 129-136.

Kiefer, N.M. (1988). “Analysis of Grouped Duration Data”. In: N. U. Prabhu (Ed.), Statistical Inference from Stochastic Processes. American Mathematical Society, Providence.

Lammers, M., H. Bloemen, and S. Hochguertel (2013). "Job search requirements for older unemployed: Transitions to employment, early retirement and disability benefits”. European Economic Review 58, pp. 31- 57.

Langenbucher, K. (2015). "How demanding are eligibility criteria for unemployment benefits, quantitative indicators for OECD and EU countries”. OECD Social, Employment and Migration Working Papers, No. 166, OECD Publishing, Paris.

Lee, D.S. (2008). "Randomized experiments from non-random selection in U.S. house elections”. Journal of Econometrics 142(2), 675-697.

Lee, D.S. and T. Lemieux (2010). "Regression Discontinuity Designs in Economics”. Journal of Economic Literature 48(2), 281-355.

McCrary, J. (2008). "Manipulation of the running variable in the regression discontinuity design: a density test”. Journal of Econometrics 142, 698-714.

Moore, D.A. and P.J. Healy (2008). “The Trouble With Overconfidence”. Psychological Review 115 (2), 502-517.

Mortensen, D.T. (1977) Unemployment insurance and job search decisions. Industrial and Labor Relations Review 30, 505-517.

Paserman, M.D. (2008). “Job Search and Hyperbolic Discounting: Structural Estimation and Policy Evaluation”. Economic Journal 118, 1418-1452.

Pedersen, J. M., M. Rosholm, M. Svarer (2012). “Experimental Evidence on the Effect of Early Meetings and Activation”. IZA Discussion Paper No. 6970, IZA, Bonn.

Rosholm M. (2008). "Experimental Evidence on the Nature of the Danish Employment Miracle”. IZA Discussion Paper No. 3620, IZA, Bonn.

Salant, S.W. (1977). "Search Theory and Duration Data: A Theory of Sorts”, In: Quarterly Journal of Economics, 91, 39-57.

Spinnewijn, J. (2015). “Unemployed But Optimistic: Optimal Insurance Design with Biased Beleifs”. Journal of the European Economic Association 13(1), 130-167.

Tatsiramos, K. and J.C. van Ours (2014). "Labor Market Effects of Unemployment Insurance Design”. The Journal of Economic Surveys 28(2), 284-311.

Tversky, Amos, and Daniel Kahneman (1974). "Judgment under Uncertainty: Heuristics and Biases”. Science 185, 1124-1131.

Vikström, J., M. Rosholm and M. Svarer (2013). "The effectiveness of active labor market policies: Evidence from a social experiment using non-parametric bounds”. Labour Economics 24, 58-67. 